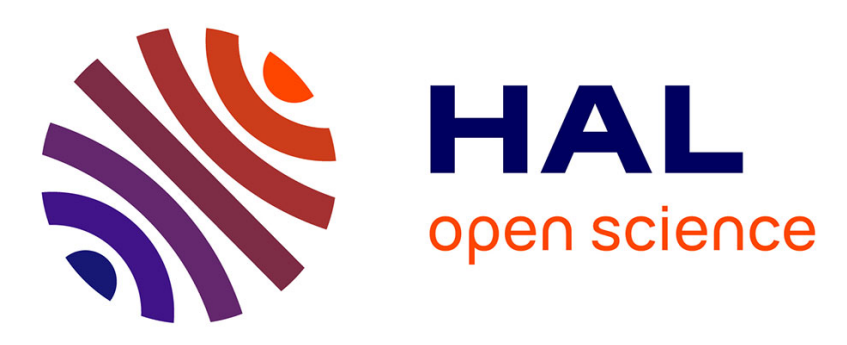

\title{
Numerical simulation analysis as a tool to identify areas of weakness in a turbine wind-blade and solutions for their reinforcement
}

\author{
Venkadesh Raman, Monssef Drissi-Habti, Laurent Guillaumat, Aghihad \\ Khadhour
}

\section{To cite this version:}

Venkadesh Raman, Monssef Drissi-Habti, Laurent Guillaumat, Aghihad Khadhour. Numerical simulation analysis as a tool to identify areas of weakness in a turbine wind-blade and solutions for their reinforcement. Composites Part B: Engineering, 2016, 103, pp.23-29. 10.1016/j.compositesb.2016.07.018 . hal-02486653

\section{HAL Id: hal-02486653 \\ https://hal.science/hal-02486653}

Submitted on 21 Feb 2020

HAL is a multi-disciplinary open access archive for the deposit and dissemination of scientific research documents, whether they are published or not. The documents may come from teaching and research institutions in France or abroad, or from public or private research centers.
L'archive ouverte pluridisciplinaire HAL, est destinée au dépôt et à la diffusion de documents scientifiques de niveau recherche, publiés ou non, émanant des établissements d'enseignement et de recherche français ou étrangers, des laboratoires publics ou privés. 


\title{
Numerical simulation analysis as a tool to identify areas of weakness in a turbine wind-blade and solutions for their reinforcement
}

\author{
Venkadesh Raman a, Monssef Drissi-Habti b, c, * , Laurent Guillaumat ${ }^{\mathrm{d}}$, \\ Aghihad Khadhour ${ }^{b}$ \\ a Department of Expertise and Research, Institut de Recherche Technologique (IRT) Jules VERNE, Chemin du Chaffault, 44340, Bouguenais, France \\ b PRES LUNAM IFSTTAR, CS4 Route de Bouaye, 44344, Bouguenais, France \\ ${ }^{\mathrm{C}}$ Director The Consortium Durability of Intelligent Composite Structures (GIS DURSI), France \\ ${ }^{\mathrm{d}}$ Arts et Métiers ParisTech, CER Angers - Laboratoire LAMPA, 2 Bd du Ronceray, 49035, Angers Cedex 1, France
}

Keywords:

Composite material

Failure criterion

Composite stitching

Adhesive bonding

Ply stacking

Wind energy

Finite element analysis (FEA)

Numerical modeling

\begin{abstract}
A B S T R A C T
Offshore wind energy is one of the main sources of renewable energy that can benefit from new generation materials that exhibit good oxidation resistance and mechanical reliability. Composite materials are the best consideration for harsh environment and deep sea wind turbine manufacturing. In this study, a numerical simulation was implemented to predict the stress distribution over a wind turbineblade and to determine areas with high stress concentration. Finite Element Analysis (FEA) was used to find optimal material and bonding techniques to construct the blade. By using Abaqus commercial software, a finite element model of wind turbine blade was analyzed under bending-torsion coupled with a static-load condition in flap-wise direction. Structural damage in critical zones varies according to ply orientation and stack thickness as a result of composite orthotropic nature. This study leads existing scenarios and techniques which would provide a new and better solutions for wind turbine blade designers. The root section and trailing edge were found to be critical zones in the wind turbine blade. The root section failure can be reduced by (1) adjusting the thickness of the structure or increasing the number of plies in the composites laminate stacking and by (2) adjusting the bonding technique to prevent trailing-edge failure. Transverse-stitch method and the carbon cord tying methods are most effective for trailing edge reinforcement. Both solutions are proposed to reduce failures in wind turbine blades and proven by step-by-step numerical study. The goal of this study is to deliver a good reference for wind turbine blade designers and to improve the accuracy during design phase as well as to avoid failure.
\end{abstract}

\section{Introduction}

Offshore wind power is defined as generating electricity from wind by the installation of seaward located wind farms. Land-based wind power will remain dominant in the immediate future but installations at sea will become more and more important. Compared to onshore, offshore wind power stations are more complex and costly to install and maintain, but have also a number of key advantages. Winds are typically stronger and more stable at sea than on land, resulting in significantly higher production per unit installed. The recent fast growth in wind energy production motivates the industry to design large scale wind-turbines, in order to reduce the cost of energy. According to the world wind energy association (WWEA), the modern wind turbines are 10 times bigger than the traditional ones [10]. As the result, the wind energy industry should adapt to advanced materials to withstand high wind forces reacting on rotor blades. Composite materials with high strength-to-weight ratio and associated stiffness are used for the production of wind turbine components.

The up-scaling of blades requires design optimization to increase strength, reduce weight as well as cost of energy. Therefore strengthening the composite material is essential for new generation blades. Our blade model, mesh, load, material and boundary conditions should be adaptable to the large scale blade. Present reviews discuss most recent developments in wind turbine blade 
Table 1

Mechanical properties of composite materials.

\begin{tabular}{|c|c|c|c|c|c|}
\hline Materials & $E_{1}$ & $E_{2}$ & $\nu_{12}$ & $G_{12}$ & $G_{23}$ \\
\hline Plain weave fabrics - Glass & $23.37 \mathrm{GPa}$ & $23.50 \mathrm{GPa}$ & 0.28 & $5.22 \mathrm{GPa}$ & $4.74 \mathrm{GPa}$ \\
\hline Plain weave fabrics - Carbon & $63 \mathrm{GPa}$ & $62.73 \mathrm{GPa}$ & 0.05 & 4.37 GPa & $2.91 \mathrm{GPa}$ \\
\hline Unidirectional - Glass & $47.10 \mathrm{GPa}$ & $13.098 \mathrm{GPa}$ & 0.28 & $4.749 \mathrm{GPa}$ & $3.134 \mathrm{Gpa}$ \\
\hline Unidirectional - Carbon & $103.3 \mathrm{GPa}$ & $9 \mathrm{GPa}$ & 0.05 & $5.32 \mathrm{GPa}$ & $3.51 \mathrm{GPa}$ \\
\hline Material & \multicolumn{4}{|c|}{ Young's modulus } & Density \\
\hline $\begin{array}{l}\text { Adhesive material } \\
\text { Foam }\end{array}$ & \multicolumn{4}{|c|}{$275 \mathrm{MPa}$} & $\begin{array}{l}1420 \mathrm{Kg} / \mathrm{m}^{3} \\
153 \mathrm{Kg} / \mathrm{m}^{3}\end{array}$ \\
\hline
\end{tabular}

numerical simulation and explore similar studies to identify relevant circumstance. Cox [21] studied structural design for largescale wind turbine blades. This article detailed a blade model with respect to industry standard failure criteria under load under extreme wind condition. Bonnet [9] studied the method of designing a blade by python scripts for Abaqus commercial software. This procedure of blade designing eases modeling process, even though the blade dimensions are variable and complicated. It is necessary to verify that the numerical results are providing appropriate information for experimental and real time structures; otherwise the numerical study has no significance for blade manufacturers. Li [42] investigated the effect of lay-up on wind turbine blade properties. A blade model was designed by shell elements and compared experimental results with numerical calculations to study the strength and mass distribution along the blade span. The significant method of meshing with shell element and load application was identified to approach the experimental condition. Ashwill [5] from Sandia Laboratory and some others [3,23] studied the coupling of bending and torsion forces acting on blades made of composites. Flap-wise direction of this load induces high magnitude force on blades. Bending and torsion loads could be sustained by optimal ply orientation and lay-up arrangement. Mechanical behavior of composite materials varies depending on the fiber stiffening directions. In light of this, the fiber direction should be selected to enhance the strength in the directions which need a high stiffness. The effect of thickness and lay-up orientation used in wind turbine blades was studied by Ref. [11]. This method helps to reduce the weight and gravitational force of wind turbine blades, also provide basic knowledge about composite material optimization. An optimization specialist in Altair [33] have investigated the ply stack sequence based on stiffness and laminate lay-up theory. He explained about free element sizing and super-ply stacking to strengthen the structure. In addition, he proposed that the $0^{\circ}$ orientation plies should be in maximum number in the direction of blade length and the $90^{\circ}$ orientation plies should be fewer for blade optimization. Ganz [15] investigated the advantage of composite materials over isotropic material. He has also studied the failure of these materials based on the Tsai-Wu criterion. The Tsai-



Fig. 1. Wind turbine blade's dimensions and load applied points.



Fig. 2. Blade designed by several planes to maintain the airfoil profile and twist angle. 
Wu method provides the failure values for each ply and helps to identify the damage for plies in various orientations. Therefore, the Tsai-Wu method was used to optimize the composite materials. Failure of wind turbine blade was also studied in various wind speed conditions based on Tsai-Wu factor, [20]. The combination of above references was used in our study to optimize wind turbine blade lay-ups and thickness. Several other papers also discuss about wind-turbine numerical study $[6,8,22,27,30,34]$. But, they lack to study edge bonding, which is used to joint upper and lower surfaces of blade.

Therefore, concentrating on the bonding of blade becomes essential for end-design. The efficient transfer of load through composite assembly requires bonded or fastened joints. Often, blade sub-components are glued together. Bonding materials become brittle after they are cured, with low brittle strength values, [4]. They lose bonding strength (stickiness) through micro-cracks. The study of bonding material is imperative to identify the strength in joining zone. Stickler [35] studied the numerical analysis as well as the effective procedure to bond composite structures. Other papers also discuss damage of composite adhesive bonding $[28,38,26,17,41]$. The main scope of manufacturers is to reduce the blade maintenance cost for offshore wind turbine blades, because maintenance expenses increase the total cost of energy in offshore installations compared to their onshore counterparts [18]). Failure in adhesive material leads to more complex maintenance, since the blades have to be detached and lowered to the ground for repairs. Thus, solutions to increase bonding strength are always profitable for new generation wind turbine blades. Tong [25] provided a good view of stitching of composite materials to increase the strength of composite bonds. $20 \%$ in peel stress can be achieved by using the transverse-stitch method. Stitching combined with bonding would reinforce the adhesive material strength based on stitching fiber and sewing pitch. This holds the blade bonding area in-place even after crack initiation [7], which increases peeling strength. The bonding zone with and without stitching was simulated and compared to extract the advantages over one to another based on Tsai-Wu isotropic failure factor. Similar to composite stitching, carbon cord introduction in the adhesive zone keeps the bonding at place even after the crack propagation [19,40].

In our model was designed with NACA 63-XXX with $70 \mathrm{~m}$ length. The simulation was done in static 3-point flap-wise bending and end point twist load. The damage in each ply was observed visually by failure factor called Tsai-Wu criterion. Adhesive bonding was included in this numerical study to clearly identify and specify bonding requirements. Therefor composite lay-up and bonding are optimized cooperatively in a single study, which reflects real time behavior of wind turbine blades. Further, a solution is proposed to overcome the identified problems for the numerical simulation.

Table 2

Thickness distribution in each section of the blade.

\begin{tabular}{llll}
\hline Section & Distance from root $(\mathrm{m})$ & Skin $(\mathrm{mm})$ & Spar $(\mathrm{mm})$ \\
\hline 1 & 0 & 49 & 65 \\
2 & 5 & 45 & 61 \\
3 & 10 & 41 & 57 \\
4 & 15 & 41 & 57 \\
5 & 20 & 37 & 53 \\
6 & 25 & 37 & 53 \\
7 & 30 & 37 & 49 \\
8 & 35 & 33 & 49 \\
9 & 40 & 33 & 44 \\
10 & 45 & 33 & 44 \\
11 & 50 & 29 & 37 \\
12 & 55 & 29 & 37 \\
13 & 60 & 25 & 29 \\
14 & 65 & 21 & 26 \\
\hline
\end{tabular}

\section{Project main scope}

The overall scope of EVEREST Project within which current work has been performed is to develop intelligent structural composite materials based on carbon fiber for the new generation of windblades that exceed $100 \mathrm{~m}$. Indeed, the switch to carbon fiber is now recommended insofar as new generations of blades with lengths greater than $100 \mathrm{~m}$ require the use of higher stiffness fibers and final composite with less-inertia, thus increasing the yield. We have established in this paper a numerical modeling which targets solely the clear identification of highly stress-concentration areas in wind blades. Once these areas are well identified, the aim is also to come-up with suggestions to help wind blade manufacturers to strengthen them, properly.

\section{Numerical analysis}

\subsection{Design}

In large scale wind turbine configurations, high area of rotation induces extreme mass flow through the blade, so blade should withstand relative forces caused by this mass flow. The numerical analysis could provide preliminary vision about the behavior of blades with low cost of investment. The blade was configured by Python codes to achieve accurate dimensions, airfoil modeling and section splines. Each component of the blade was programmed independently and assembled in Abaqus commercial software. The blade was designed by quadratic 2D shell elements, Fig. 4 , the blade root is considered as circular section and towards tip the blade gets the form of an airfoil. The airfoil profile NACA 63-XXX (full airfoil name kept confidentially) series was used to design the blade. In this model, the blade was designed by a skin and box-beam spars. Real-time blades contain ribs and other additional structures inside the skin to provide high strength, but consideration of the whole structure would complicate the analysis. Thus, only skin and spars were selected to study material properties and an improvement of rigidity. The blade length is $70 \mathrm{~m}$ and chord length at the root corresponds to $3 \mathrm{~m}$. The chord length at the tip was considered as $1.5 \mathrm{~m}$. The blade has a twist throughout the span, this twist is assumed to be $15^{\circ}$ from root to tip. In other words, the root plane and tip plane are orientated by $15^{\circ}$ from one to the other. Spar is considered as box beam section, fixed with skin. The spar contains spar cap, which is placed between $15 \%$ and $50 \%$ of the chord length of the airfoil, withstand the bending forces and the chordwise inertial forces [29]. The shear webs help to withstand the shear forces acting on the large scale assembly. The following Fig. 2 shows the designed aerodynamic configurations and the final model of the blade in Abaqus user interface.

In this model, we have considered adhesive as isotropic material [38]. Thin layer located between the upper and lower section is modeled with shell element from root to tip, shown in Fig. 20. This helps to design the bonding without affect the leading and trailing edge geometries. The section thickness of adhesive layer is $40 \mathrm{~mm}$, see Fig. 21. Composite blades are bonded generally by adhesive materials with high shear modulus and tensile rigidity to avoid the separation of the blades even at the critical wind loading. Adding adhesive materials in numerical analysis, helps to study precisely about stress distribution over the length of the blade and the adhesive material properties.

\subsection{Boundary conditions}

Off-shore wind turbine blades undergo random wind forces. The Wind flows across the blade at diverse velocities in different environmental conditions from random directions. It is impossible 
to consider all these states of wind effect for blade designers. Therefore, the maximum wind force, which acts on the blade, is calculated by standard methods, in order to find out the boundary condition for the numerical study. The international standard called IEC-61400-1 gives the complete criterion that should be respected for the blade design in extreme conditions [10]. The focus of this study was the load caused by extreme wind shear (EWS) conditions in parked blades.

The blade element momentum theory is used to find the acting aerodynamic forces based on blade cross section area [10]. The blade element momentum theory (hereafter represented as BEM) assumes rotor blades can be divided into several elements based on the cross-sectional area and angle of attack along the blade span. The elements are called span-wise annular elements. The airfoil produces lift and drag forces based on the cross section variation. For BEM calculations, two assumptions are made to calculate aerodynamic coefficients.

1. No aerodynamic interactions between the blade elements.

2 . The aerodynamic coefficient is calculated only under lift and drag coefficients.

It is also assumed that the axial and tangential velocities are uniformly distributed all over the annular elements. The overall performance of the blade is determined by numerical integration of element forces along the span of the blade. The blade section is exposed to the wind speed $V_{0}$ called axial velocity. The tangential velocity is represented by $r \omega$. The axial velocity is reduced to $(1-a)$ $V_{0}$ and the tangential velocity is moved to $\left(1+a^{\prime}\right) r \omega$. The $\mathrm{W}$ is known as relative velocity. The angle between the relative velocity and the rotor plan is the inflow angle, $\phi$. The twist $\theta$ is defined as the angle from the rotor plant to the chord line. The angle between the relative velocity and the chord line is an angle of attack.

In this figure, $R$ is radius of blade rotation and $r$ is radius of annular element, $\mathrm{dr}$ represents the thickness of the annular elements (Fig. 5), $\omega$ represents the angular velocity, a is axial induction factor related to the power coefficient. $\mathrm{C}$ is the chord of the airfoil.

$\alpha=\phi-\theta$

$\tan \phi=\frac{1-a}{1+a \prime} \frac{V-0}{r \omega}$

Abbot and Doenhoff mentioned that the lift and drag forces per length can be calculated from the rotor blade section's lift and drag coefficients as:

$l=\frac{1}{2} \rho W^{2} c c_{t}$

$d=\frac{1}{2} \rho W^{2} c c_{d}$

c - chord length

$c_{t}-$ lift coefficient

$c_{d}-$ Drag coefficient

The thrust and torque of the annular elements are derived as follows

$d T=\frac{1}{2} \rho W^{2} c B c_{y} d r$ $d Q=\frac{1}{2} \rho W^{2} c B c_{x} r d r$

$c_{x}$ and $c_{y}$ is calculated and they are used in the thrust and torque equation

$c_{y}=c_{t} \cos \phi+c_{d} \sin \phi$

$c_{x}=c_{t} \sin \phi-c_{d} \cos \phi$

When applying all the coefficients and the derived values in the $\mathrm{dT}$ and dQ equation, we can get the thrust and torque equations of a finite number of blade's elements as:

$d T=\frac{1}{2} \rho V_{0}^{2} 4 F a(1-a) 2 \pi r d r$

$d Q=\frac{1}{2} \rho V_{0}^{2} 4 F(1-a) a^{\prime} \frac{\omega r}{V_{0}} r 2 \pi r d r$

F is Prandtl correction number, $a^{\prime}$ tangential induction factor and $u_{t}$ is the tangential velocity caused by the wake rotation. From Equation (4), we can calculate the thrust force acting on each blade elements. The thrust force is converted to the bending load according to the direction of load application, we have selected flapwise direction load. Based on EWS conditions, wind shear also causes twist force at the blade tip.

In this paper the blade was simulated in linear static condition under coupling of bending and torsion loads [3,23]. Combined bending and torsion loads are applied as shown in the equation (4).

$\left[\begin{array}{cc}E I & -g \\ g & G J\end{array}\right]\left[\begin{array}{l}\frac{\partial \theta}{\partial x} \\ \frac{\partial \phi}{\partial x}\end{array}\right]=\left[\begin{array}{l}M_{b} \\ M_{t}\end{array}\right]$

Coupling limit $\alpha$

$\alpha=\frac{g}{\sqrt{E I . G J}}$

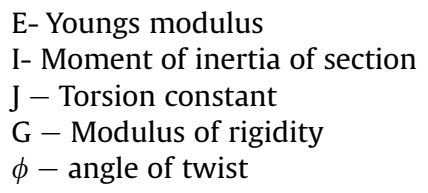

\subsection{Materials}

\subsubsection{Composite materials}

Many materials were used for constructing wind turbine blades in former times. Nowadays, designers are primarily working with fiberglass composites (GFRP). The increase in rotor size and various other constraints motivate to work with new materials or to use the current material, but modified. The majority of blades are modeled by using glass fiber composite; adding carbon fibers in certain percentages will increase the stiffness and reduce the weight of the structure [6]. Carbon nano-tubes and plant fiber composites also start to enter the wind turbine domain $[13,16]$. In this study, only Carbon/epoxy composite (CFRP) and glass/vinyl ester composites (GFRP) were considered [32].

Skin and spar are the two main components used in this study. Other substructures were neglected for simplification. Spar is a longitudinal beam section, which has two parts called spar-web 
Table 3

Blade failure criterion value and deflection for different composite material's ply orientations.

\begin{tabular}{|c|c|c|c|c|}
\hline Serial No & Ply orientation & Material & Tsai-Wu & Tip deflection in $\mathrm{m}$ \\
\hline 1 & Cross Ply & Plain weave Carbon fiber composite & 0.485 & 7.764 \\
\hline 2 & Cross Ply & Uni directional Carbon fiber composite & 1.252 & 9.010 \\
\hline 3 & Cross Ply & plain weave Glass fiber composite & 0.9273 & 20.55 \\
\hline 4 & Cross ply & Uni directional Glass composite & 2.449 & 16.99 \\
\hline 5 & Angle ply & Plain weave Carbon fiber composite & 1.071 & 30.6 \\
\hline 6 & Angle ply & Uni directional Carbon composite & 1.749 & 26.39 \\
\hline 7 & Angle ply & Plain weave Glass composite & 1.279 & 30.21 \\
\hline 8 & Angle ply & Uni directional Glass composite & 2.064 & 31.98 \\
\hline 9 & Multi-ply & Plain weave Carbon fiber composite & 0.732 & 10.62 \\
\hline 10 & Multi-ply & Uni directional Carbon composite & 1.786 & 11.56 \\
\hline 11 & Multi-ply & Plain weave Glass composite & 1.107 & 24.05 \\
\hline 12 & Multi-ply & Uni directional Glass composite & 3.236 & 20.12 \\
\hline
\end{tabular}

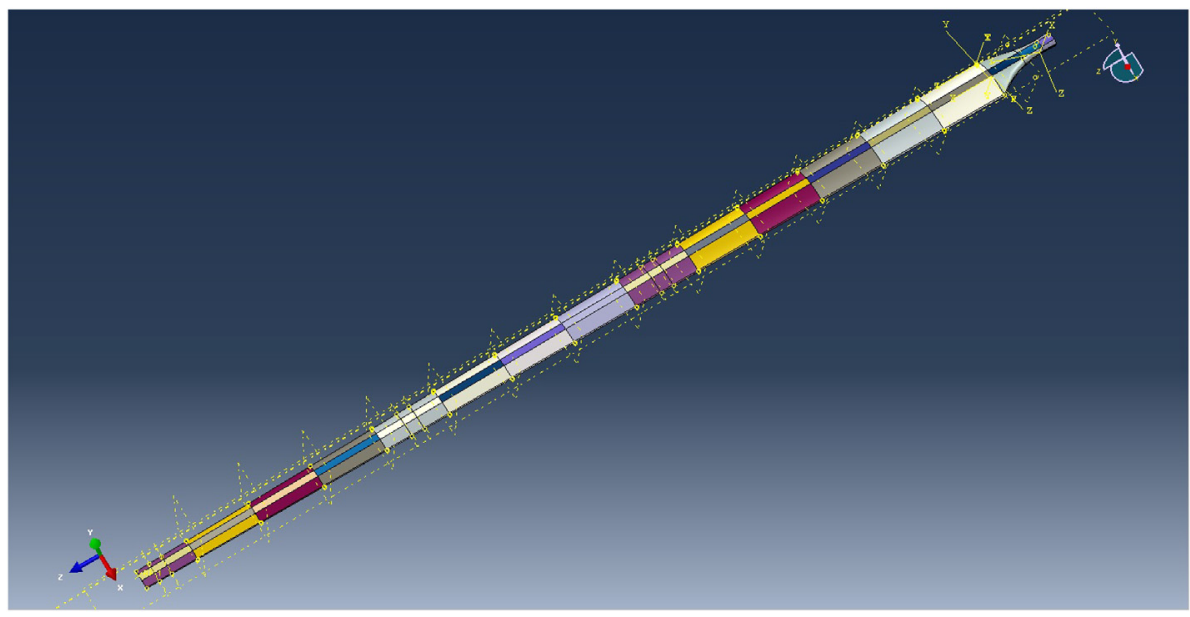

Fig. 3. Division of blades into more sections to define the material properties and thickness.

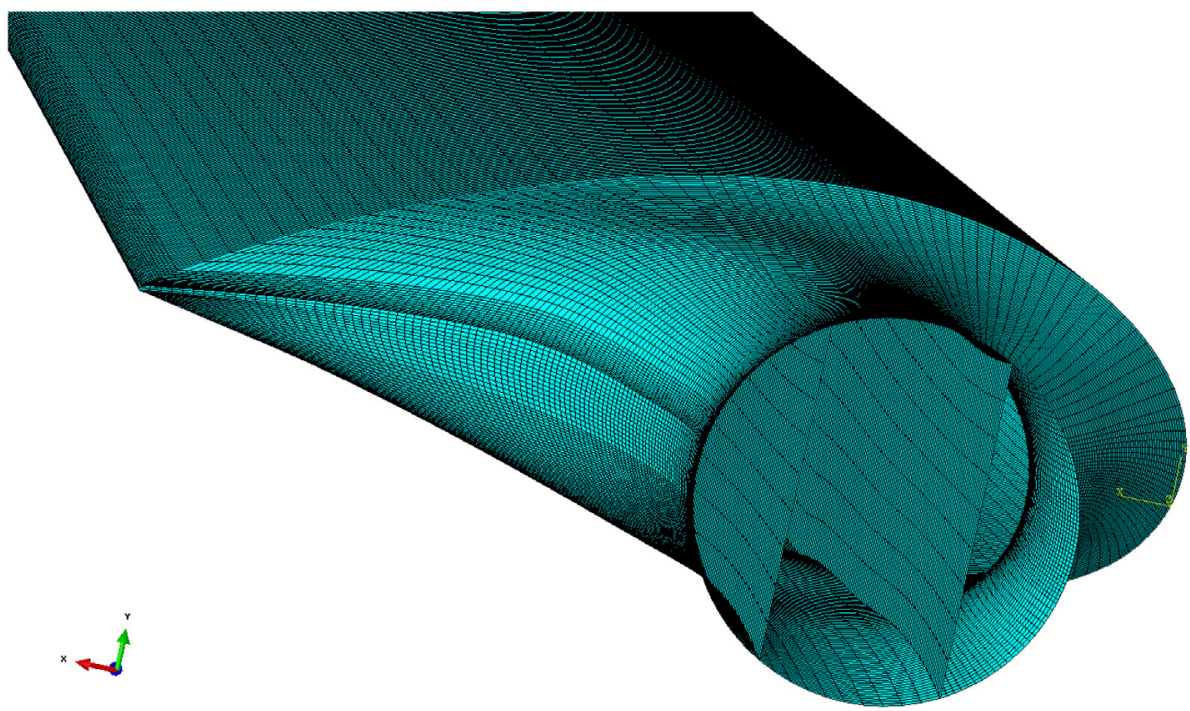

Fig. 4. Blade mesh model.

and spar-flange. The spar web, which was made of a sandwich material, contains foam as a core [14]. The material's mechanical properties are shown in Table 1. The skin of the sandwich structure was designed by glass or carbon composites [31]. Sandwich material provides very good resistance against shear loads. The spar flange was designed with unidirectional composite tapes to provide high bending stiffness.

As wind turbine undergoes random wind loads, blade skin should be made of the material, which has rigidity in all directions, therefore, the skin was modeled with plain weave fabric composites. For industrial applications, designer selects weave composites rather than unidirectional composites because of their strength 




Fig. 5. Division of wind turbine rotor into annular elements for blade element theory the fixation that leads to matrix crack, fiber breakage and delamination of plies at several cycles of blade operations. The adhesive materials provide enough sticking force between the upper and lower section of the blade. Therefore, blade components are bonded with high strength adhesive material.

Adhesive material properties are studied in a single lap joint model that reveals clearly the stress components in peel and shear direction, [35]. The load is applied to two adherends as traction forces in opposite directions. Both adherends are considered orthotropic material. The adhesive material is considered isotropic material, as the mechanical properties same in all directions $[38,41]$. The adherends are assumed to act as linear elastic cylindrical bend plates under plain strain conditions. For adhesive materials, shear and normal stress components within the adhesive layer are nonlinear functions. $U$ subscript represents upper adherend and $\mathrm{L}$ subscript represents lower adherend. This helps to differentiate the adherends in the following explanation. Semianalytic field equation is given in Ref. [38]. The related adhesive stress and moment values were obtained from the force equilibrium condition and constitutive relations. Fig. 19 shows the section cut of the force and moment reacting on the single lap joint. These

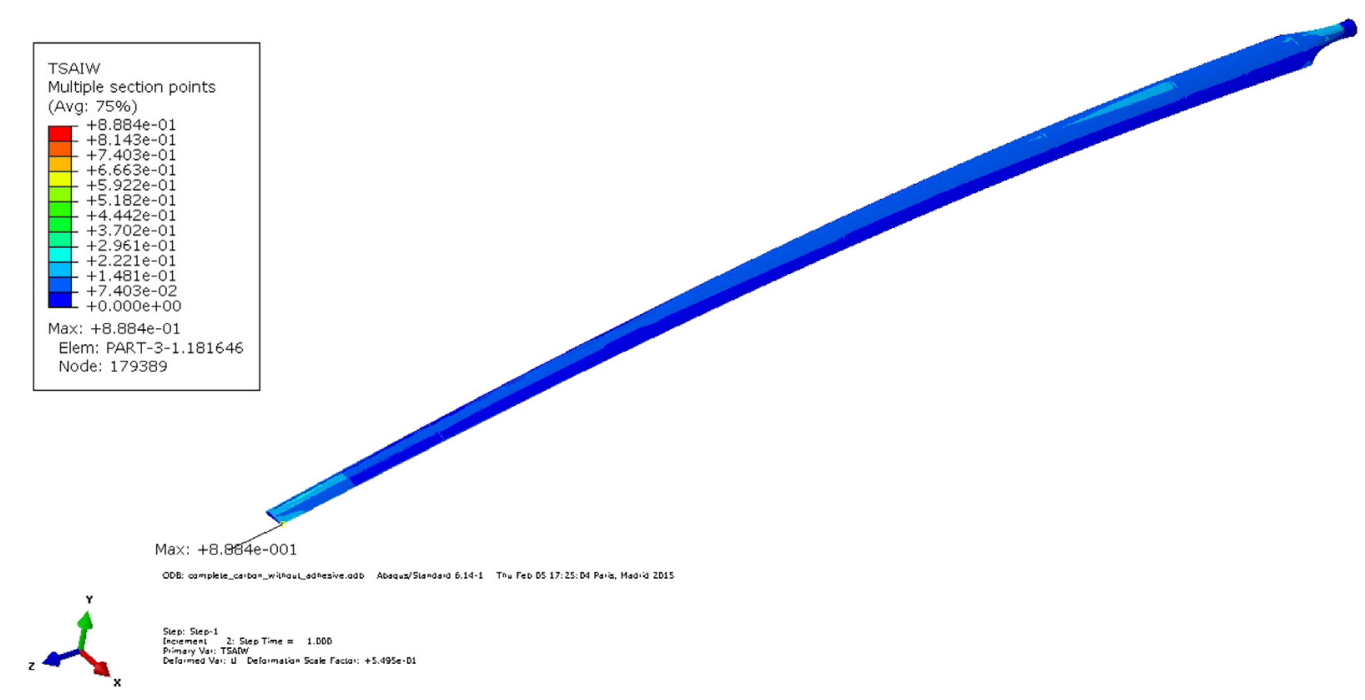

Fig. 6. Failure values of carbon composite made skin.

dispersion in all directions (see Fig. 8), but they have negligible disadvantage according to fatigue performance [29]. Unidirectional composites are better if the force is applied along the longitudinal direction of the fiber. Transverse modulus of the unidirectional composites is too low compared to the longitudinal modulus. The leading edge section was considered to have foam to resist direct contact (impact) causing by wind flow.

\subsubsection{Adhesive material}

An adhesive layer is included in our simulation to identify their characteristics against bending-torsion coupling load. Before that, it is important to know the reason to focus on adhesive materials and the stress components acting in adhesive zones. Composite rotors are manufactured in an autoclave by different methods like compression molding, vacuum assisted resin transfer method [10]. They are made by two sections (upper airfoil and lower airfoil section, see Fig. 20) and they are fixed by proper adhesive materials and bolts. The adhesive material fixation is preferable for wind turbine blade because bolts make high-stress concentration around forces and moments are derived from equilibrium condition to extract the joint equilibrium equation with known components. The end overlap region is subjected to $N_{0}, M_{0}, Q_{0}$, at the same time the resultant force, stress and moment are defined as $Q_{x}, N_{x x}$, and $M_{x x}$. These six components will provide six field equations for the corresponding bonded single lap joint [38]. In the adhesive layer, $\varepsilon_{z z}$ denotes the normal component of linear strain and $\gamma_{x z}$ shows the engineering shear strain.

In addition, material properties are used to simplify the equations based on total plasticity theory and Von-Mises yield criterion to determine the force and moment resultants and the onedimensional strain field in the adhesive layer as a function of joint length. The final equations are derived as follows. $E_{s}$ and $\mu_{p}$ denotes inelastic properties of adhesive material.

$$
\sigma_{z z}=\frac{E_{s} \varepsilon_{z z}}{\left(1-\mu_{p}^{2}\right)} \cdot \varepsilon_{z z}
$$




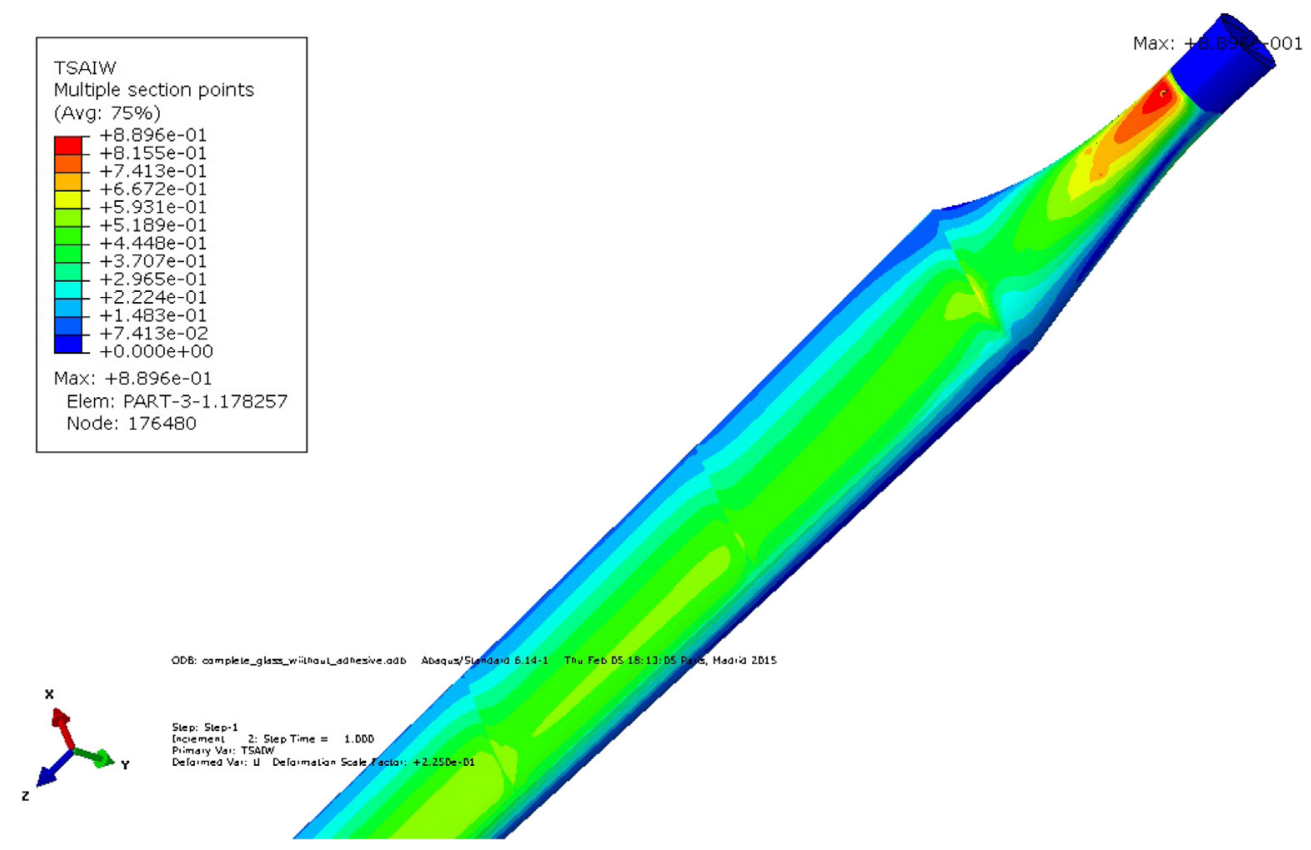

Fig. 7. Failure values of glass fiber composite made skin.

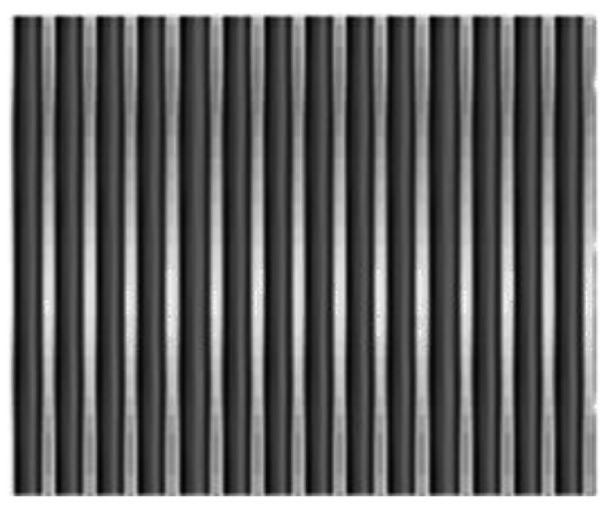

(a) Unidirectional tape

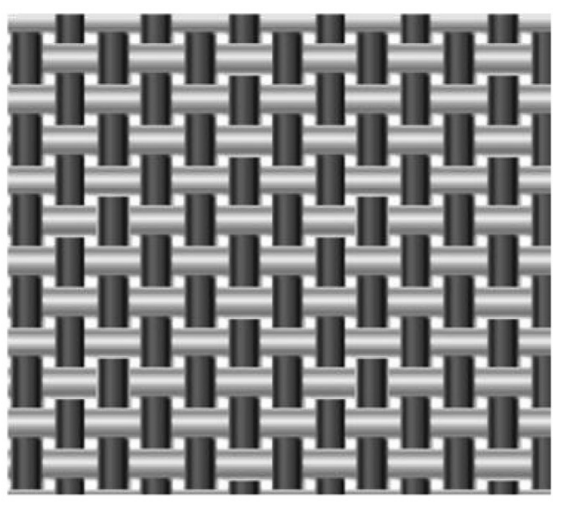

(b) Plain weave

Fig. 8. (a) Unidirectional tape composite, (b) Plain weave fabric composite. Source [36].

$\tau_{x z}=\frac{E_{s} \gamma_{x z}}{2\left(1+\mu_{p}\right)}$

$\sigma_{z z}$ and $\tau_{x z}$ represent the normal and shear stress respectively. This analytic model concludes the stress acting on adhesive material in any type of structure. Macroplast-UK1340 type adhesive properties are used in this simulation [1,2].

\subsection{Failure criterion}

In this numerical simulation, Tsai-Wu failure factor was used to identify the damages in orthotropic and isotropic materials [15,20]. Tsai-Wu theory is a simplified form of Gol'denblat and kopnav's generalized failure theory for materials. The failure criterion equation for orthotropic materials which contains three coordinate directions is given below. There is no coupling effect between normal and shear stress components.

$$
\begin{aligned}
& \left(\frac{1}{T_{11}}-\frac{1}{C_{11}}\right) \sigma_{11}+\left(\frac{1}{T_{22}}-\frac{1}{C_{22}}\right)\left(\sigma_{22}+\sigma_{33}\right) \frac{\sigma_{11}^{2}}{T_{11} C_{11}} \\
& \quad+\frac{1}{T_{22} C_{22}}\left(\sigma_{22}+\sigma_{33}\right)^{2}+F_{12} \sigma_{11}\left(\sigma_{22}+\sigma_{33}\right)+\frac{1}{\sigma_{23}^{2}}\left(\sigma_{23}^{2}\right. \\
& \left.\quad-\sigma_{22} \sigma_{33}\right)+\frac{1}{\sigma_{12}^{2}}\left(\sigma_{12}^{2}+\sigma_{31}^{2}\right) \\
& \quad \leq 1
\end{aligned}
$$

where.

$\mathrm{T}$ - Maximum tensile tress

C - Maximum compressive stress

$1,2,3$ are plane directions

$\sigma-$ stress acting on the structure by applied force

For isotropic materials, the Tsai-Wu failure equation is reduced 


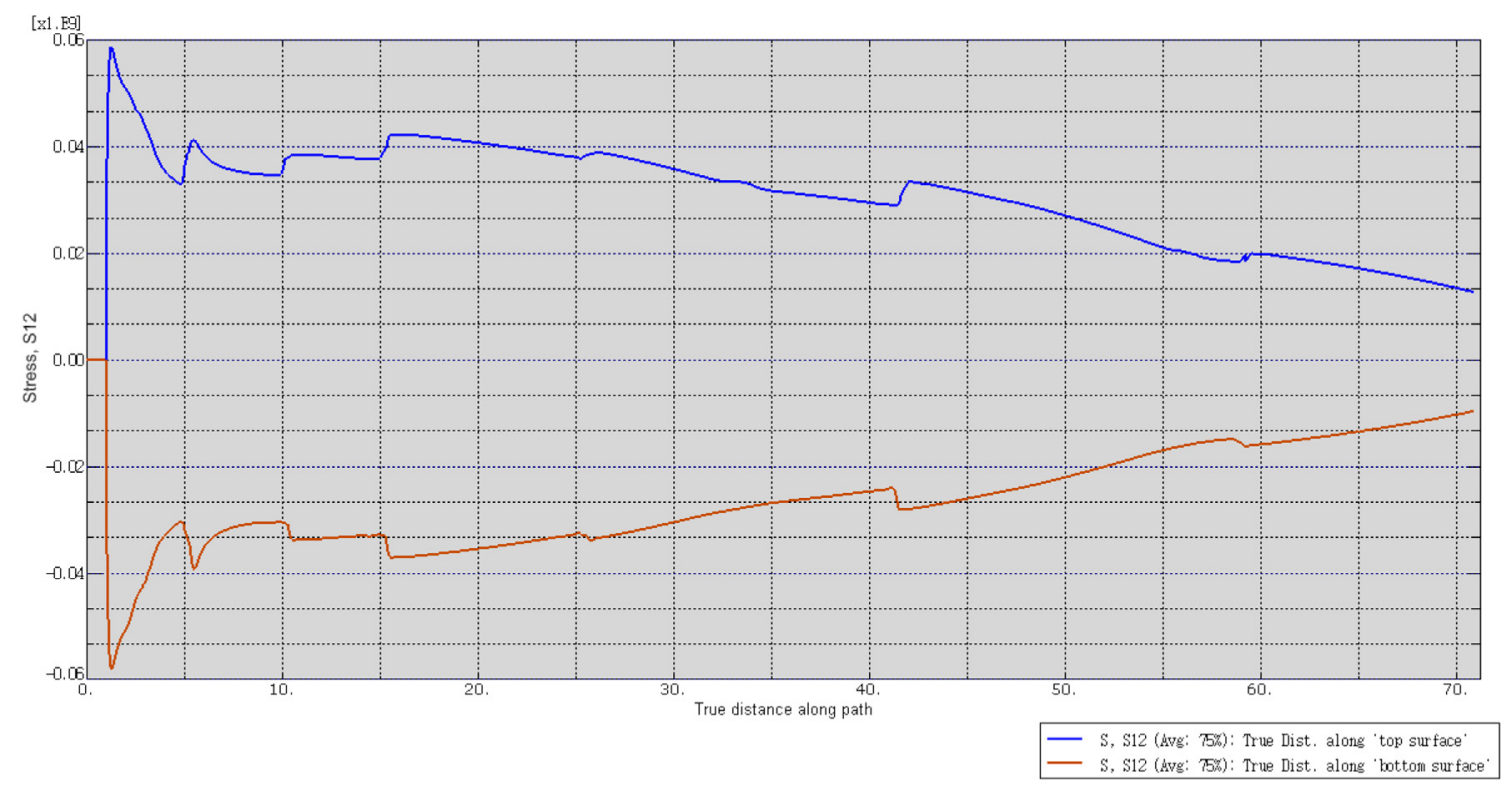

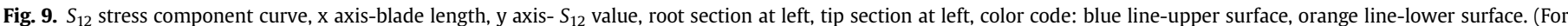
interpretation of the references to colour in this figure legend, the reader is referred to the web version of this article.)

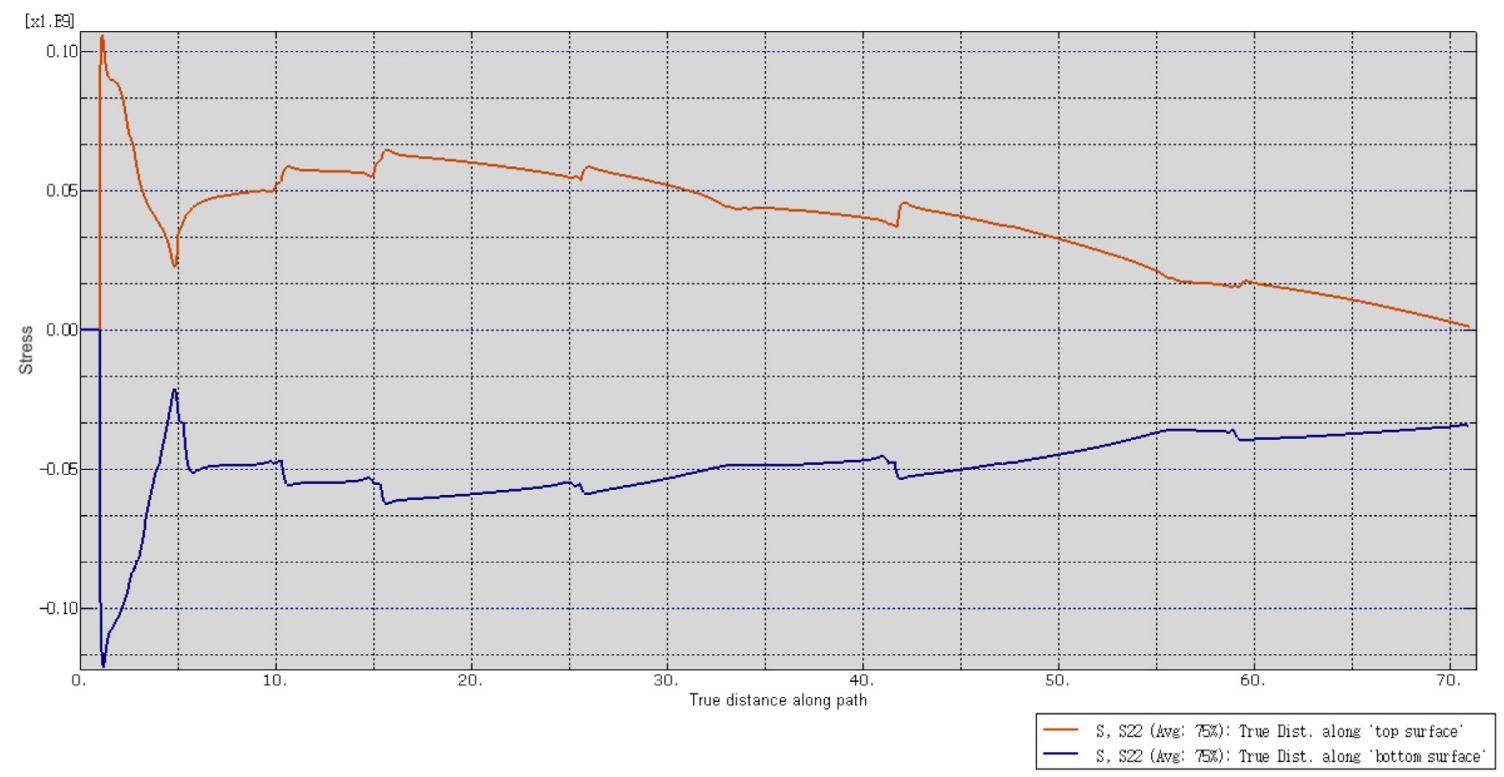

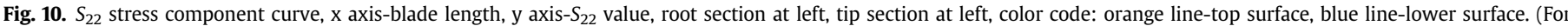
interpretation of the references to colour in this figure legend, the reader is referred to the web version of this article.)

to plans 1 and 2 . Hence, these coefficients are equal to the coefficient in principle plane directions. From this failure criterion, we observe that the failure criterion value should be less than one for the materials undergo damage within the safety level. If the value is more than one that proves that the damage in the structure is beyond the safety margin.

\section{Results}

\subsection{Composite lay-up}

The simulation was carried out under linear static condition using Abaqus. The $150 \mathrm{KN}$ force was applied at points a, b, c mentioned in Fig. 1. For the initial time, the blade thickness was maintained constant throughout the span and no bonding properties are introduced in the numerical model for better analyzing the composite material properties. The result of numerical analysis provides Tsai-Wu value of failure, the author doesn't focus on blade buckling. The top and bottom surfaces follow various stress values; e.g: The basic shear stress $S_{12}$ and bending stress $S_{22}$ acting on the blade are shown in Figs. 10 and 9 consecutively. The top surface undergoes positive stress (tensile stress), the bottom surface under goes negative stress (compression stress).

From Table 3, we can assume that the weave fabrics offer advantages over unidirectional fiber composites. The tip displacement values show that the carbon composite provides high stiffness along the loading direction. E.g: if we consider Serial number 1 and 3 in the table, we observe that weave cross ply-carbon 


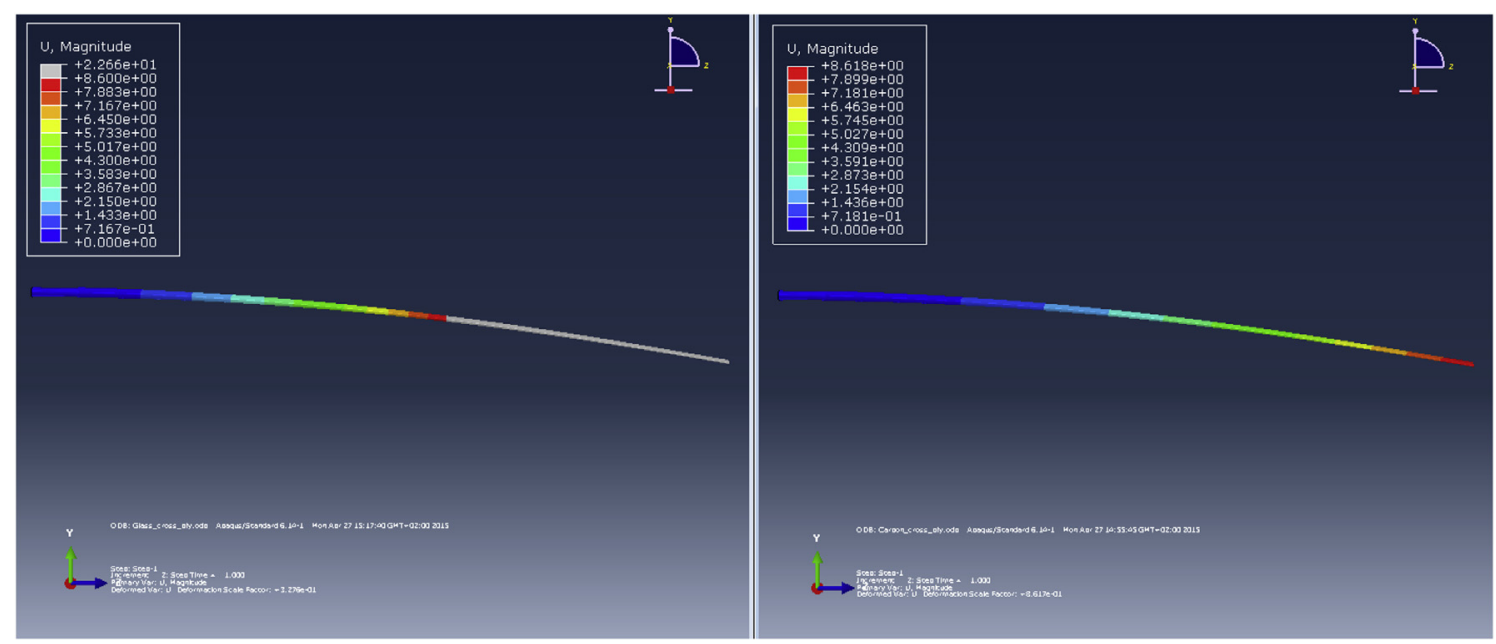

Fig. 11. Deflection of GFRP blade (left), deflection of CFRP blade (right), GFRP deflection = CFRP deflection + grey color zone (additional deflection).

Table 4

Properties of blade after segregation to sections.

\begin{tabular}{llll}
\hline Type & Tsai-Wu criterion & Deflection & weight \\
\hline Type-1 & 0.88 & $13.52 \mathrm{~m}$ & $25671 \mathrm{Kg}$ \\
Type-2 & 0.89 & $32.98 \mathrm{~m}$ & $34894 \mathrm{Kg}$ \\
Type-3 & 0.95 & $28.4 \mathrm{~m}$ & $29455 \mathrm{Kg}$ \\
\hline
\end{tabular}

configuration provides $7.7 \mathrm{~m}$ tip deflection; in the same time weave cross ply-glass configuration provide $20.55 \mathrm{~m}$ deflection. These deflections are shown in Fig. 11, we observe visually that the carbon blades deflect merely half of the deflection realized in the glass blade. This proves that the carbon fiber composites have more strength and stiffness compare to glass fiber composites.

* Cross ply $-0^{\circ} / 90^{\circ}$

* Angle ply $-45^{\circ} /-45^{\circ}$

* Multi-ply $-0^{\circ} / 90^{\circ} / 45^{\circ} /-45^{\circ}$

Secondly, we are comparing the properties of architecture between weave ply and unidirectional ply. E.g.: In Table 3, note down the values in serial no 1 and 2, we found that the blade with carbon cross ply-weave configuration undergoes less tip deflection compare to carbon cross ply-unidirectional configuration $(9.010) \mathrm{m}$. This variation is not having much difference, but the failure values are having remarkable differences. Weave plies provide only 0.48 failure value and unidirectional plies deliver 1.252 failure value. Analyzing the unidirectional configuration reveals following statement; Plies with $0^{\circ}$ undergo less failure, but the plies with $90^{\circ}$ offer high level of failure, which leads the unidirectional composite towards some inconvenience of causing harm to the structure (Figs. 13 and 15). Because the damage in a single ply would propagate to the whole structure by means of delamination and cracks. This proves the advantage of weave composite over unidirectional composite.

\subsection{Bonding}

Bonding properties are introduces in our numerical model and submitted under the same load condition. High-stress concentration occurs in bonding that is located at trailing edge, because bonding materials rigidity is lesser than the composite material. As we observe in Fig. 24a, the damage occurs at the end of trailing edge for all configuration. We assume the damage was caused by the torsion load. Bending load have some influence on bonding material failure, but their effect is lesser than torsion load. The failure values exceed beyond the safety limit mentioned by Tsai-Wu factor (see blue bars in Fig. 25). This failure value is shown in the numerical simulation with a red color zone in Fig. 24a. From this result, we can note that the adhesive bonding alone is not efficient to fix the blade with $70 \mathrm{~m}$ length. Reinforcement in the adhesive region is needed to withstand high stress in the adhesive assembly area.

\section{Optimization}

\subsection{Lay-up optimization}

Additionally, the advantages of fiber orientation are analyzed in this chapter. cross ply, Angle ply and multi-ply configurations are used in this study (Fig. 12). E.g: mind serial number 1 and 5 in the Table 3, we note that cross ply configuration have more advantage compare to angle ply configuration. Especially glass fiber composites are having low stiffness with high flexibility, which leads to tip deflection of $30.6 \mathrm{~m}$. While considering serial number 4 and 8 in the table, we observe that the tip deflection is always higher for the angle-ply configuration. But the failure value becomes low for angle ply-unidirectional glass composite (S.No-8) compare to the cross ply-unidirectional glass composite (S.No-4). Because failure in $45^{\circ}$ is lower than $90^{\circ}$ ply as shown in Fig. 14, this generates large failure value in cross ply-unidirectional glass blade. Also, glass fibers have very good shear properties, therefore, glass fibers produce better failure resistance, while the plies are oriented in $45^{\circ}$. Multi-plies always provide the values in between the cross and angle ply, because of the combination of all orientations in it. The prominent advantage with multi-ply is less number of $90^{\circ}$ plies and the combined effect of shear properties provided by $45^{\circ}$ plies.

Therefore, to select the material properties for further chapters, we have made following assumption from previous discussions. Wind turbine blades undergo bending load and wind shear force, loads may act in any direction. So the material properties should be selected as per the wind condition. Some components need high stiffness and strength in all direction, like skin and spar flange. But some components need more flexibility and strength toward the longitudinal direction, like spar cap. Tip deflection should be selected in the moderate range. If the deflection is high, the blade would undergo oscillation; if the deflection is too low, the blade 




will resist too much of load which may lead to structure damage. The stiffness should be correct enough to withstand the bending load with acceptable deflection. Therefore from above explanation, we assume that the material with weave-multi-ply configuration is suitable for skin to resist wind shear. The unidirectional type composites are suitable for spar cap. The spar web is made of a sandwich material with angle ply materials in the skin of sandwich.

After observing this preliminary result, we created lay-up rule for our blade model 63-XXX. Lay-up stacking in the spar web section is shown in Fig. 16. Skin and leading edge stacking orientations are mentioned in Figs. 17 and 18 respectively. $0^{\circ}$ ply with violet color, which represents isotropic material, has a property of foam material [(TYCOR)]. As seen, the skin of the blade is aligned in multi-ply orientation. More $0^{\circ}$ plies were added to improve the rigidity. The first and last plies of the skin is maintained $45^{\circ}$ to act against shear stress concentration by the wind. The Choice between carbon and glass would be based on the cost, weight and environment $[31,39]$.

\subsubsection{Thickness and component material optimization}

After studying the material stacking sequence and architecture, the thickness of the blade should be optimized in order to reduce the weight and the gravitational force of the blade. Also this helps to avoid the stress concentration at root section. Span was divided according to the angle of twist, span length equivalent to $1^{\circ}$ twist angle is considered as one section, this way was followed for $15^{\circ}$ angles. This segmentation also allows defining different material thickness and orientations. Also, this difference in thicknesses in various sections causes the ply drop effects. To avoid the ply drop effect during the calculation, we have considered a lot of $0^{\circ}$ plies inbetween the other plies [33]. Each ply is designed with $1.25 \mathrm{~mm}$ thickness. Blade thickness was calculated from the radius of a rotor and bending load [11]. From Figs. 9 and 10, we can identify that the root section is highly influenced by shear and normal stress components. Therefore thicker section of composite is expected in this zone. An iterative program was created to find the optimal ply section thickness for our model. The resultant dimensions are shown in Table 2, this shows the thickness values used in the spar cap and the skin from root to the tip section. Fig. 3 shows, how the blade model looks after its segregation. Each section, we can define different material property and thickness. Failure value of the blade after the thickness variation is shown in Figs. 6 and 7. Fig. 6 indicates the failure of blade with carbon material (Type-1), Fig. 7 shows the failure of blade with glass material (Type-2). We also tested the Type- 3 configuration, which would be the possible solution to reduce the weight and cost. The failure of Type- 3 blade is roughly similar to Type- 2 blade failure. The mass of the blade based on material type indicate that the Type- 3 blade has some advantages over Type-2, see Table 4. Carbon fiber weighs lesser than glass fiber that leads to weight reduction in Type-3 blade.

skin and spar cap made of carbon (Type-1),

skin and spar cap made of glass (Type-2),

Glass skin and spar cap made of carbon (Type-3).

Type-1, Type-2 and Type- 3 configurations show approximatively the same value of failure (see Table 4), but the location of failure origin is different between carbon skin blade and glass skin blade (see Figs. 6 and 7). Type- 1 failures at trailing edge and Type-2 and Type-3 failures at root section. But, Tsai-Wu value became lower than 1 for all configurations after thickness was adjusted. For Type-1, the failure concentration takes place at the leading and trailing edge's tip, because of lacking of shear property in carbon to resist torsion load. But Type-2 and Type-3 configurations show high stress at the root (see Fig. 7), the reason that the glass fiber 

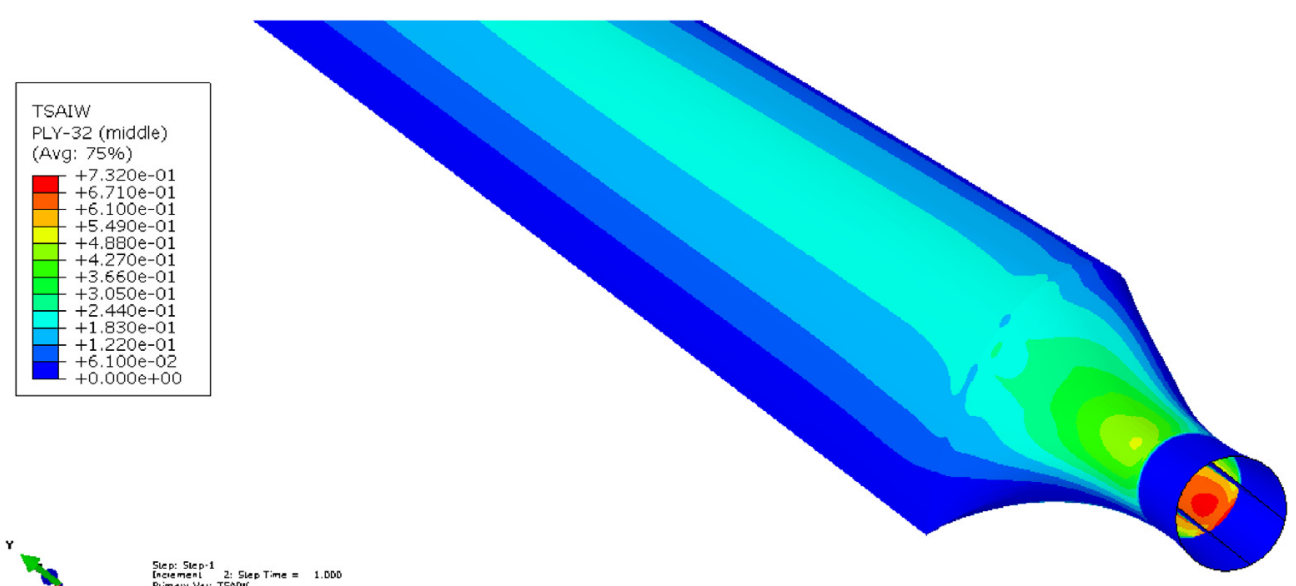

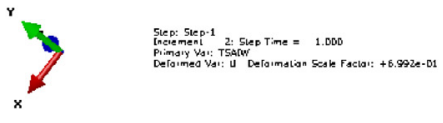

Fig. 13. Tsai-Wu failure criterion value of $0^{\circ}$ ply at Type- 1 configuration.
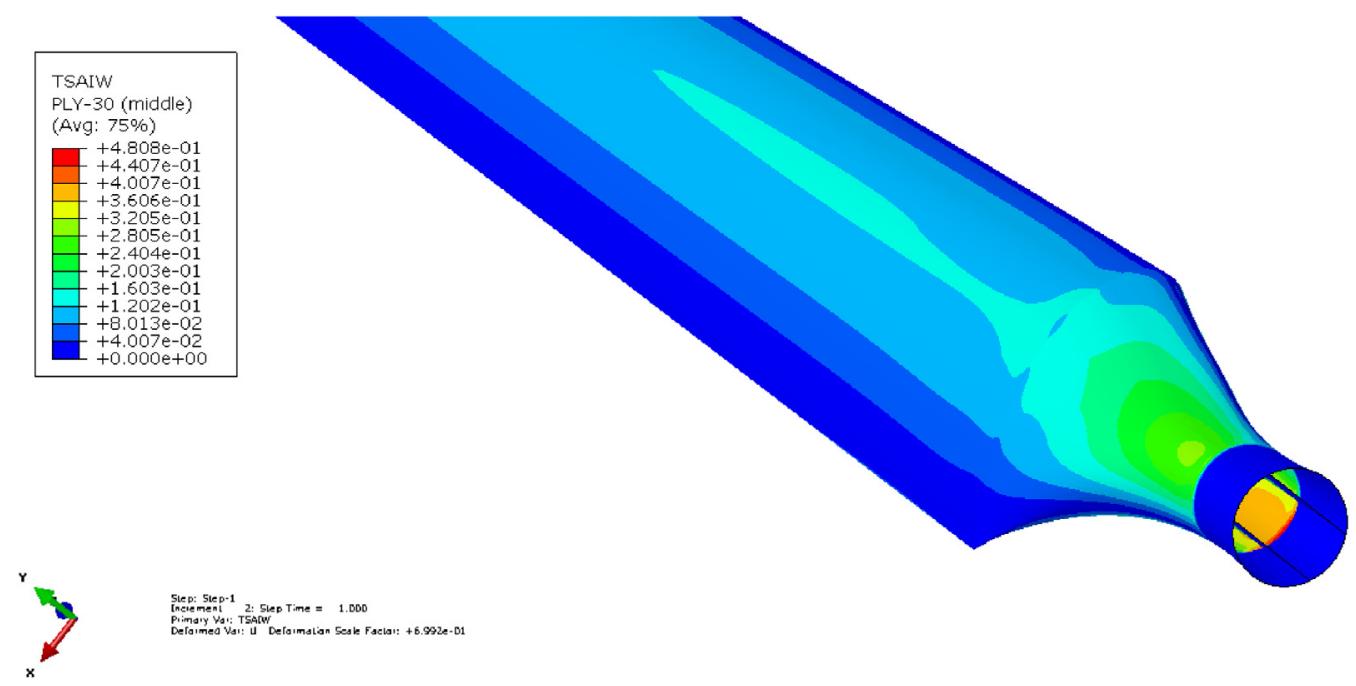

Fig. 14. Tsai-Wu failure criterion value of $45^{\circ}$ ply at Type- 1 configuration.
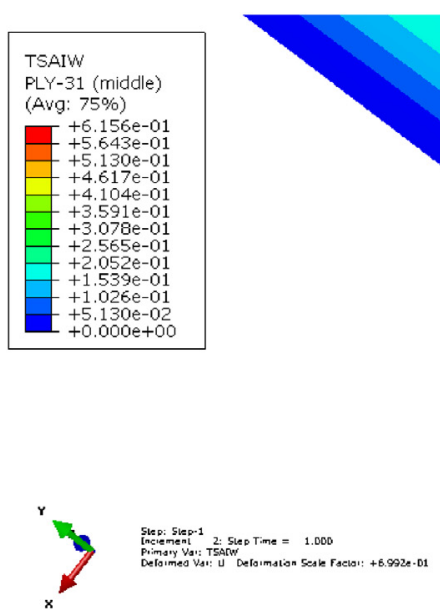

Fig. 15. Tsai-Wu failure criterion value of $90^{\circ}$ ply at Type- 1 configuration. 


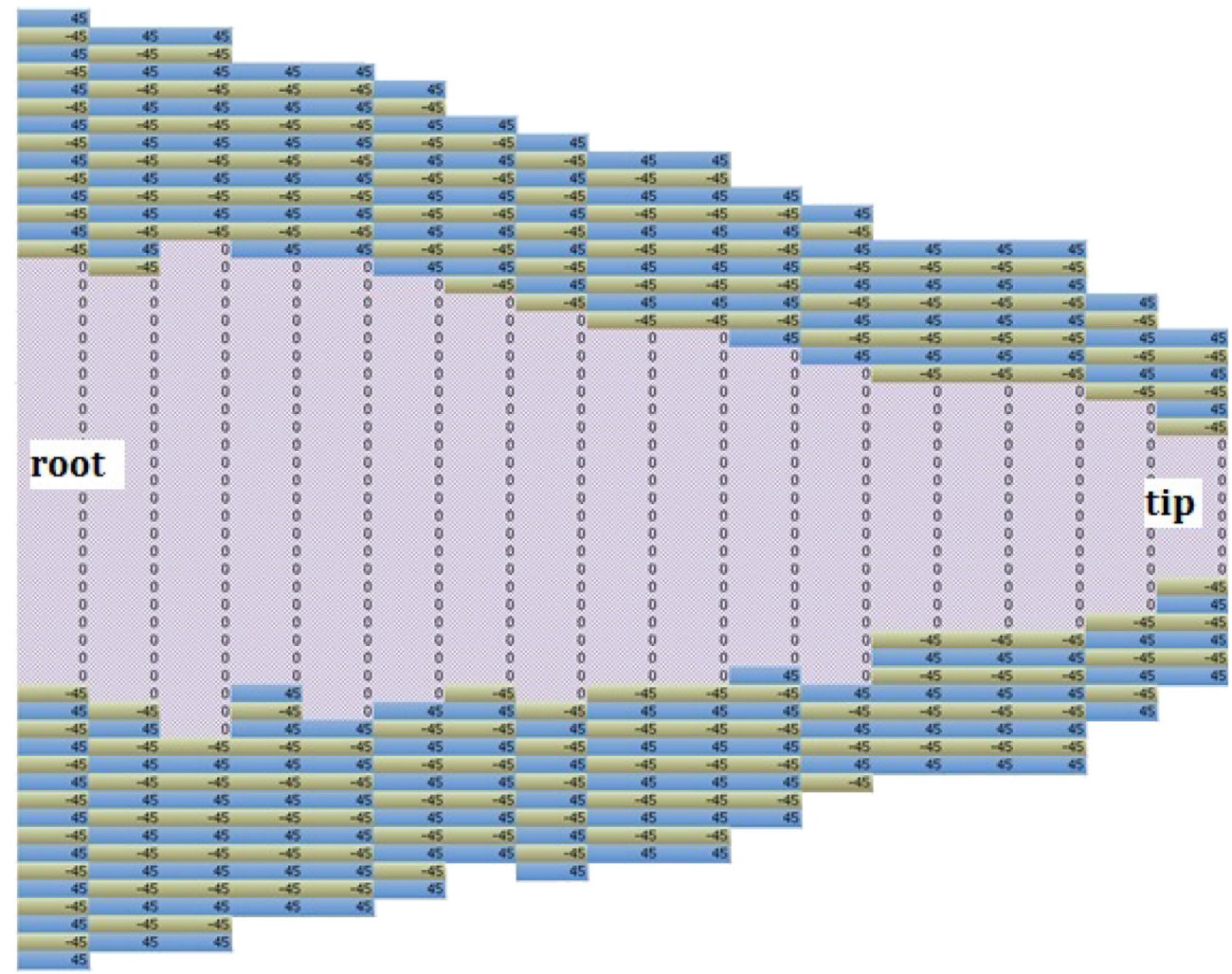

Fig. 16. Composite lay-up stacking for spar web section.

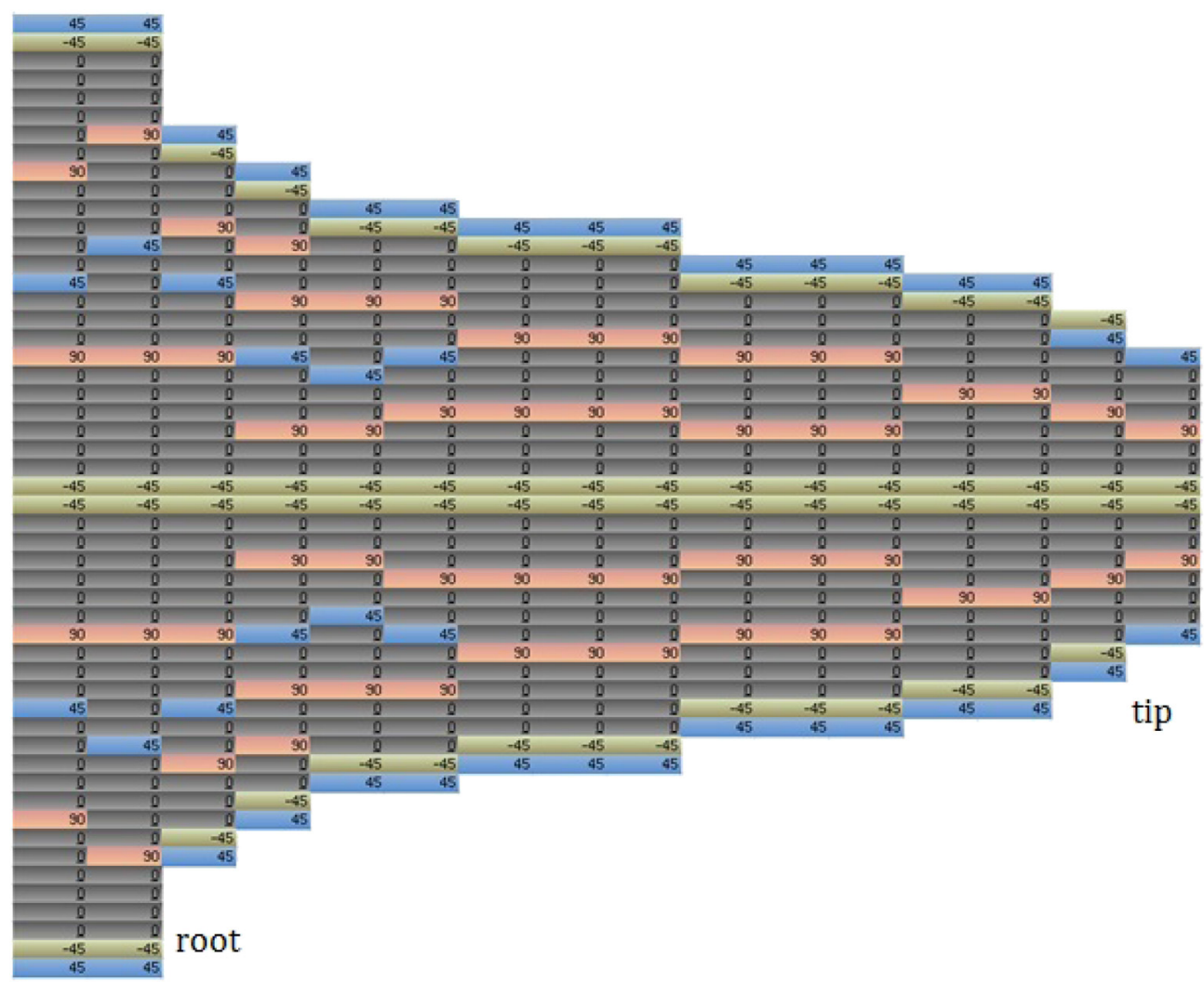

Fig. 17. Composite lay-up stacking for skin. 


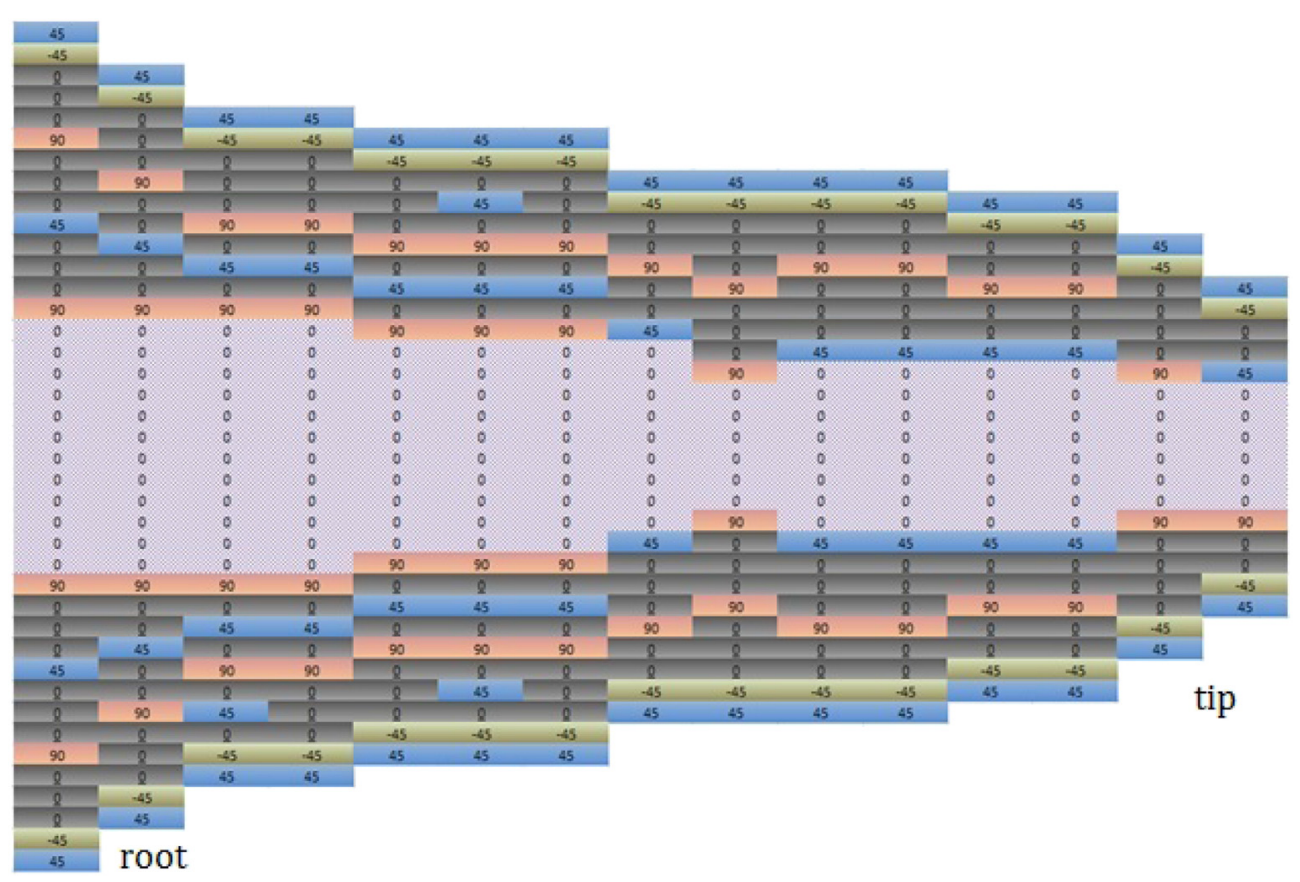

Fig. 18. Composite lay-up stacking for leading edge.

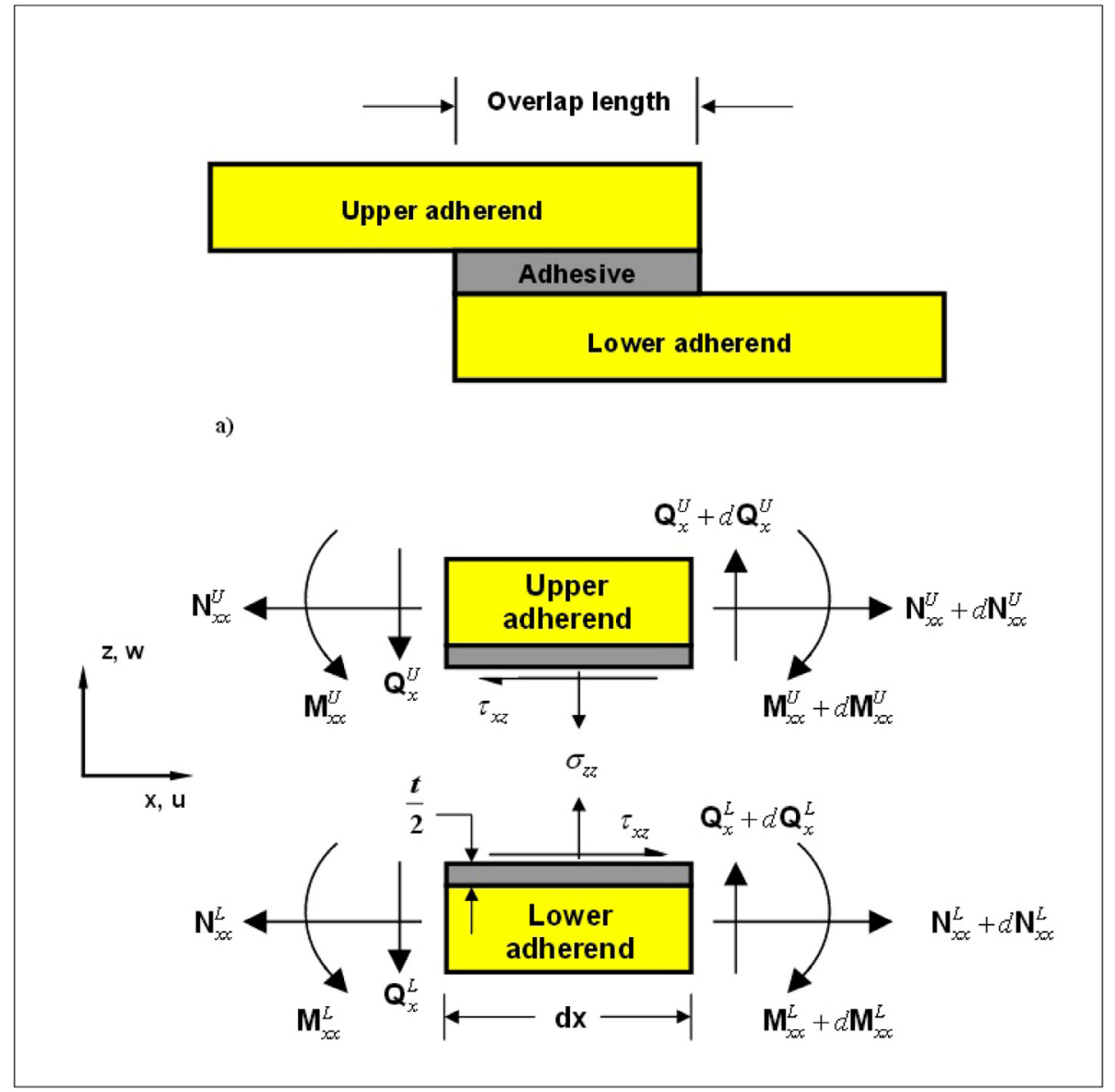

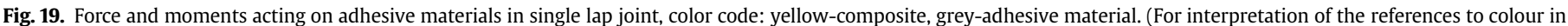
this figure legend, the reader is referred to the web version of this article.)

Source: [38]. 


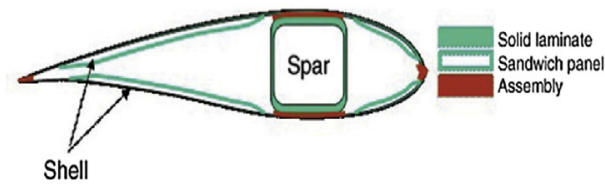

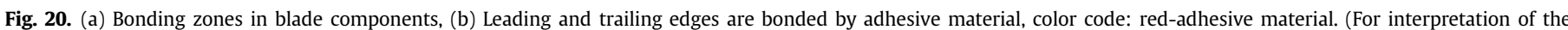
references to colour in this figure legend, the reader is referred to the web version of this article.)

Source: $[1,24]$.
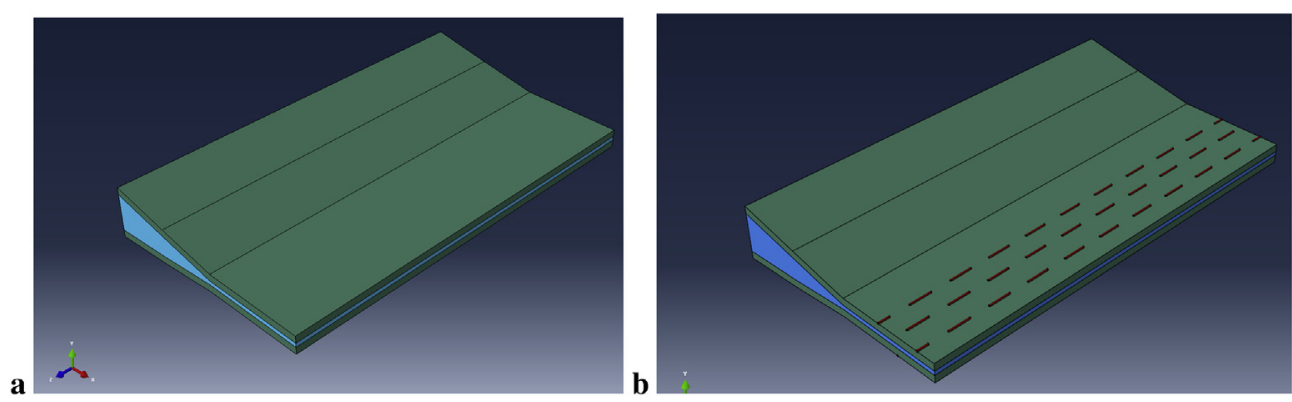


references to colour in this figure legend, the reader is referred to the web version of this article.)

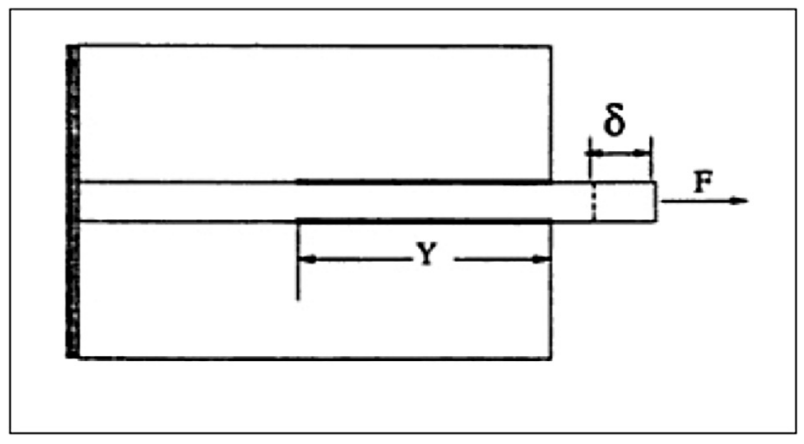

Fig. 22. Forces and displacement of threads in composite stitching, Source [13] Source: [25].

composite has less bending strength. In addition, they are providing more shear strength against torsion load to limit the trailing edge failure. Significantly this result reports that the Type- 1 configuration affected by torsion load, other two configurations are affected by bending load.

\subsection{Optimization of bonding material}

As seen in previous results, adhesive bonding alone is not sufficient to withstand a high load, also, bonding zone is the weakest area where damage gets initiated. Therefore, the advanced composite assembly called stitching is proposed in this paper. This technology help to avoid stress concentration in trailing edge bonding zone. Tong [25] provided Equations 10 And 11 to prove the addition of shear and peeling resistance through the use of composite transverse stitching in bonding. The stitching properties are studied also with the single lap joint with two adherends and adhesive material in the connecting area. The adhesive layer has longitudinal and lateral displacements. Stitching contributes to

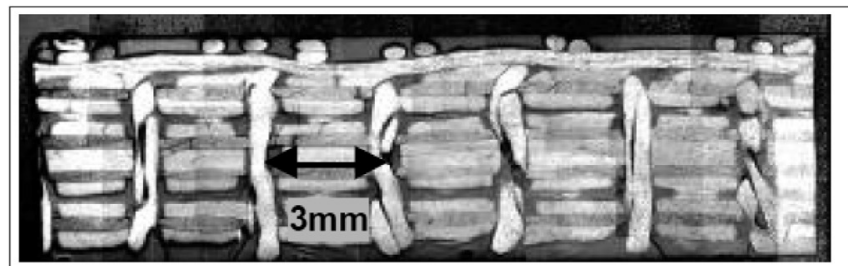

(a) Cross-section of a symmetrically layered, stitched composite.

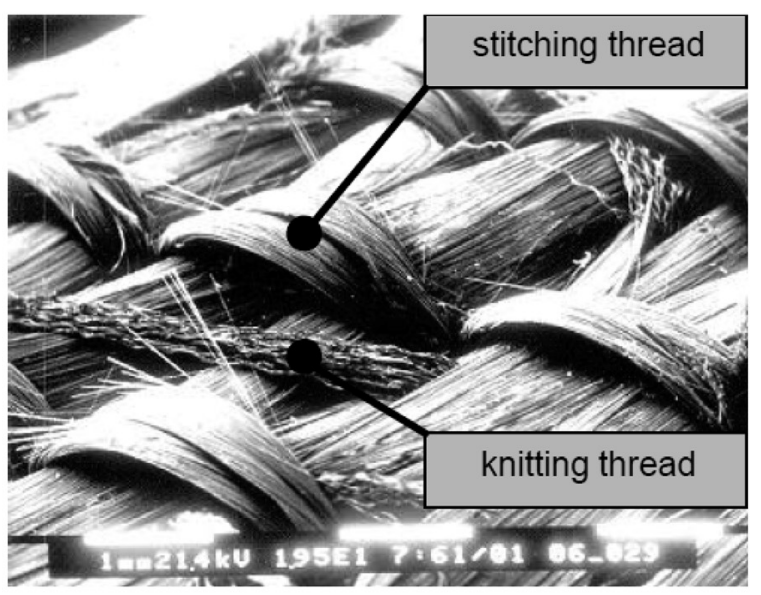

(b) Images from scanning electron microscope: $3 \times 3 \mathrm{~mm}^{2}$ stitched CFRP warp knitted fabric.

Fig. 23. (a) Composite fabric stitching, (b) Scanning microscopic images of Stitching fibers.

Source: [12]). 

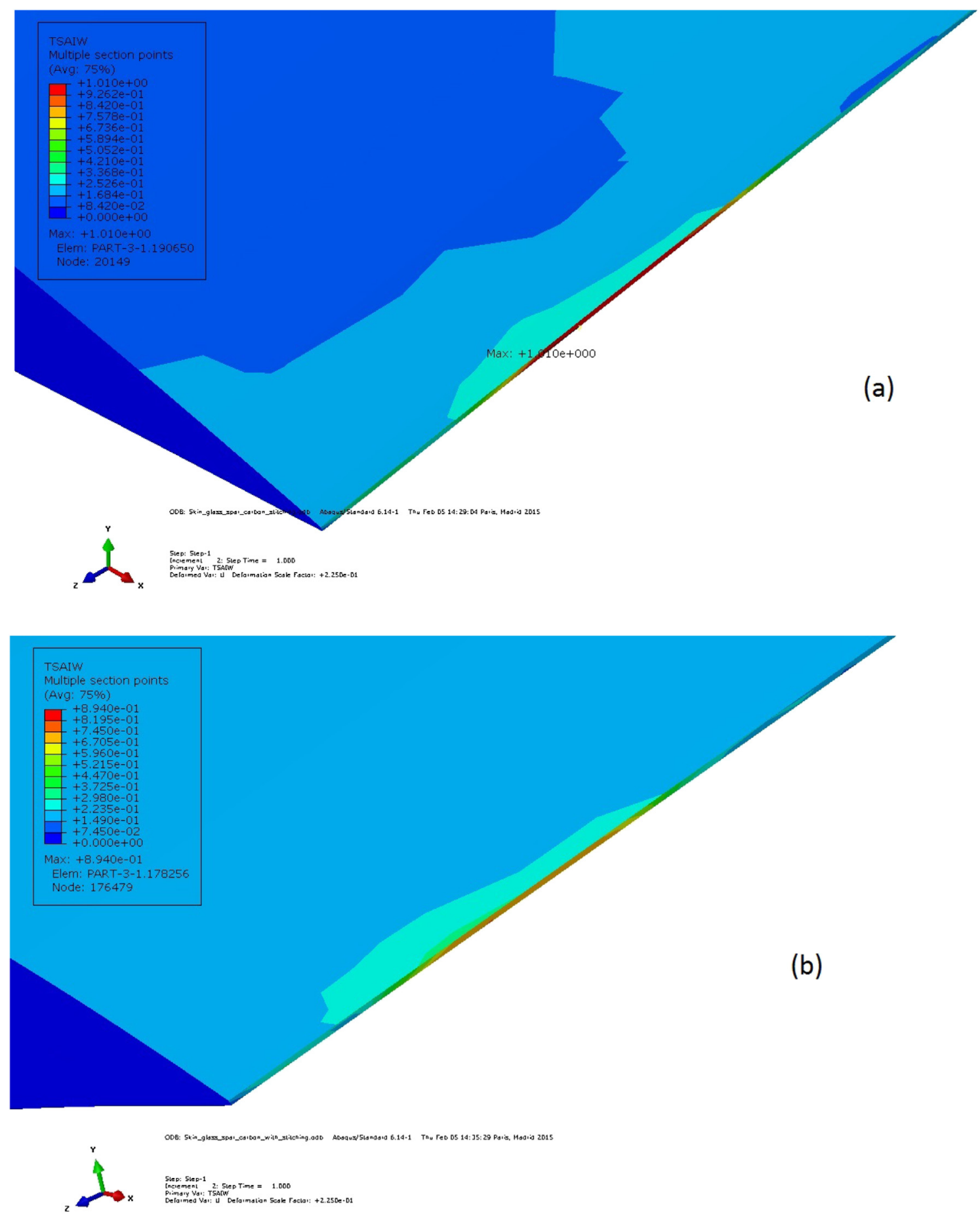

Fig. 24. (a) Failure in trailing edge bonded by adhesive material, (b) Failure in trailing edge bonded by adhesive material and stitching.

both peel and shear stress in the bond. Tong equation gives 7 first order differential Equations [25].

When the overlap is reinforced by transverse stitching through both adhesive and adherends, the contribution from the transverse stitching threads to peel and shear stress are provided as follows. $\gamma$ is a shear strain, $\varepsilon$ is a normal strain.

$\tau^{*}(\gamma)=\tau(\gamma)+\tau_{s}(\gamma)$

$\sigma^{*}(\varepsilon)=\sigma(\varepsilon)+\sigma_{s}(\varepsilon)$
While applied load increases in the model, stitching threads stretch between both the top and bottom adherends proportional to load values. The stitching thread shares the stress with the adhesive material, this allows low-stress concentration to the adhesive material, Fig. 22. Forces more than the threshold level are carried-out from adhesives by means of stitching threads. Following equations explain the reaction of threads in joints. $Y$ is a length of the stitch that carries a load, also known slip length, $\mathrm{H}$ is single stitch length embedded in the matrix. As the load F carried by the thread get increased, the slip length increases from 0 to $\mathrm{H}$ 


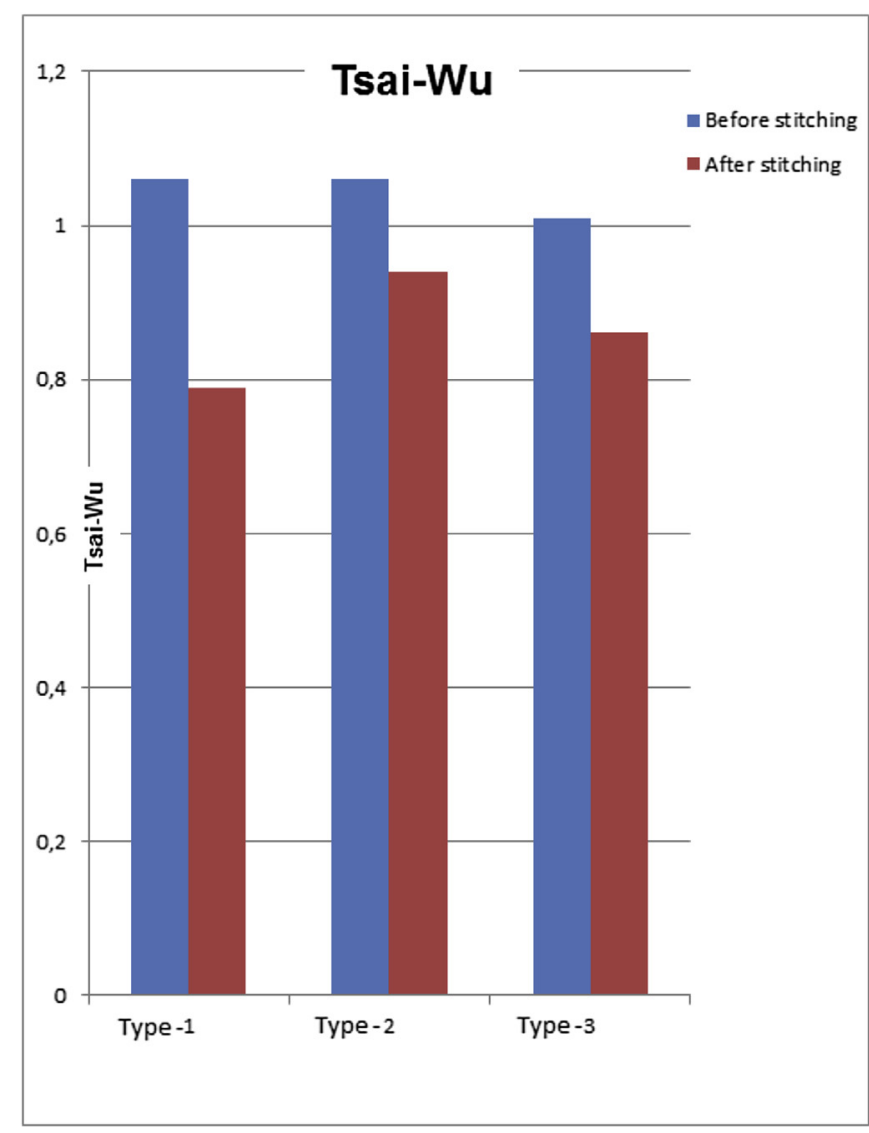

Fig. 25. Tsai-Wu value before and after the stitching parameters are entered in the simulation, Vertical axis values represent Tsai-Wu criterion.

provided that the thread does not fail. In Equation (12), $F_{t}$ is assumed as constant along the whole length of the stitching. Force and displacement equations are reduced as follows,

Force $=F(\delta(Y))=\tau_{i} \pi d_{f} Y+F_{t}$

$$
\begin{aligned}
\text { Displacement } & =\delta(Y) \\
& =\left[Y-\frac{H}{r}\left(1+\varepsilon_{t}\right) \ln \left(1+\frac{Y r}{H\left(1+\varepsilon_{t}\right)}\right]\left[+\frac{Y r}{H\left(1+\varepsilon_{t}\right.}\right]\right.
\end{aligned}
$$

This gives,

$F=\tau \pi d_{f} H_{1}+\frac{A_{f} E_{f}}{H_{1}}\left[\sigma_{2}\left(1+\frac{F_{t}}{A_{f} E_{f}}\right)-\frac{H_{1} r_{1}}{2}\right]+F_{t}$ for $\sqrt{\frac{2 H \delta}{r}\left(1+\varepsilon_{t}\right.} \geq 1$

$\delta=\left(\frac{\gamma^{2}}{2}+\varepsilon\right) t$

where.

$$
\begin{aligned}
& A_{f} \text { Cross section of the fiber } \\
& E_{f}-\text { Young modulus of fiber } \\
& d_{f}-\text { Diameter of the fiber } \\
& r-\text { Extensibility ratio } \\
& F_{t}-\text { pretension in the thread }
\end{aligned}
$$

Once the force and displacement for a stitch thread are determined, the peel and shear stresses are calculated as shown in
Equations (14) and (15). These values are added to the shear and peel stress values obtained in Equations (8) and (9) to get the property of stitching reinforced adhesive bonding. From these single lap joint resultant equations, we observed that adhesive material properties are reinforced in the joints by the presence of stitching. Both equations are functions of shear-strain and force acting on threads. Therefore, the thread should be selected to reduce the shear strain value in order to reduce the overall stresses in bonding zones. This analytic deduction clearly proves the reinforcement of adhesive zones by stitching [25]. also found that the stitching increases $20 \%$ of peel and shear strength in the adhesive joints [37]. studied the adhesive strength based on fatigue parameters, and he proposed that $38 \%$ of adhesive strength is increased by the presence of stitching. This improved bonding parameters proposed by tong were added in our numerical simulation at the joints.

$\sigma_{s}=F\left(1-\frac{\gamma^{2}}{2}\right)$

$\tau_{s}=F \gamma$

The result from this final model shows failure value for all 3 configurations. Type- 1 provides the failure value of 0.78 , which is lower compared to the joint without stitching (26\%), see Fig. 24b. failure in Type-2 decreases from 1.03 to 0.92 , this brings the failure factor less than safety limit, but still close to the margin. And Type-3 configurations provide Tsai-Wu values in between other 2 configurations, see Fig. 25. The Type- 1 configuration provides less failure factor, because the weak shear property of the carbon material and the peel strength of bonding is reinforced by composite stitching (equations (10) and (11). Here, a strength of carbon and strength of stitches are performing together to reinforce the zone, see Fig. 23. Therefore, the damage value got reduced. This combined effect of damage resistance is less for glass fiber material, that makes the failure value close to safety limit for Type- 2 configuration. Type- 3 configuration performs like Type- 2 configuration, but the presence of carbon fiber in the spar give good stiffness to reduce the failure value. Note that all three configurations show the failure value less than 1 , which is a major advantage collected from stitching. composite cord tying would be one of the best solution similar to stitching, in order to increase the adhesive resistance, Fig. 21 but this may cause the local damage which is under study. This study proves that the composite stitching is really useful for wind turbine blade assembly, especially while we using carbon materials, we can obtain a noticeable reduction in failure. It is worthwhile to note that the solutions that were listed must be viewed as suggestions only. The cost-effective way to enhance the resistance of the bonding will be the one that manufacturers will select, based on technological and financial basis.

\section{Conclusion}

The $70 \mathrm{~m}$ blade numerical model was successfully analyzed step by step. Blade skin was made of weave fabric composite, spar cap consists unidirectional fiber tapes in order to provide longitudinal strength and spar-web and leading edges were made up of sandwich material to produce shear resistance. This combination was supposed to resist utmost windy condition.

After that, material properties have to be optimized, in order to withstand flap-wise bending-torsion coupling load. Blade root section and trailing edge were found highly failure zones under this boundary condition. Each section thicknesses has been optimized with a view of reducing the blade weight. The optimal lay-up stacking sequences were found for each component of the blade. Skin consist multi-ply stacking sequence with more $0^{\circ}$ plies and 
spar-web sandwich skin is made up of angle ply laminates. We have achieved an appreciable reduction in failure value of root section after this optimization. Carbon and glass material selection is based on the requirement (cost, weight and stiffness) of blade designer, therefore, we have provided the result for the scenarios with each of these materials.

Secondly adhesive bonding was fairly added in the numerical model, it was added between a high and low-pressure side of airfoil section of the blade. Torsion load have more influence in trailing edge failure when blades are bonded by the adhesive material. Adhesive materials are not easy to optimize, as they have isotropic behavior. It is easily possible that bonding material separate from the composite blade components. Therefore attaching bonding and composite material by means of additional reinforcement would help to reduce the failure. The technique called 'stitching' was considered and proved to improve the adhesive material damage. This stitching brought $26 \%$ of reduction in failure for macro scale blade made of carbon composite material in numerical study. For both glass and carbon made blades, the failure value falls under the safety limit. Our numerical study proves that the adhesive bonding with stitching is highly advised to reinforce the bonding zones in the large-scale wind turbine blade. Further research on this project would improve the numerical simulations close to the real manufacturing process.

\section{References}

[1] Consulted at: 2015-02-13. Techncal data sheet - Macroplast UK 1340-B90.

[2] Consulted at: 2015-02-13. Technical data ,sheet Tycor W-series type foam materials.

[3] Al-Bahadly Ibrahim. Wind turbines - adaptive bend-torsional coupling wind turbine blade design imitating the topology structure of natural plant leaves. InTech; 2011.

[4] Carpinteri Alberto, Paggi Marco. Influence of the interface bonding strength on brittle crack propagation in bi-material structural components. In: 15th European Conference on Fract (ECF); 2004.

[5] Ashwill Thomas D. Passive load control for large wind turbines. In: 51st Aiaa Asme/Asce/Ahs/Asc structures, structural dynamics, and materials conference 2010.

[6] Asseff Nicholas S. Design and finite element analysis of ocean current turbine blade Mts/Ieee Biloxi - Marine Technology for Our Future Global and Local Challenges 1-6. 2009.

[7] Aymerich Francesco. Effect of stitching on the static and fatigue performance of Co-cured composite single-lap joints. J Compos Mater 2004;38:243-57.

[8] Sorensen Bent F, Jorgensen Erik, Debel Christian P, Jensen Find M Jensen Henrik M, Jacobsen Torben K, et al. Improved design of large wind turbine blade of fibre composites based on studies of scale effects (Phase 1). Summary Report Risø-R-1390(EN). 2004.

[9] Bonnet Paul A, Dutton Geoff. Parametric modeling of large wind turbine blades Abaqus UK regional user meeting. 2007.

[10] Brøndsted Povl, Nijssen Rogier PL. Advances in wind turbine blade design and materials. Woodhead Publishing; 2013.

[11] Zhang Chenyu, Wang Simon, Xie Huimin. Static structural analysis of parked composite wind turbine blades. In: Proceedings of the 8th international conference on structural dynamic; 2011. p. 3395-9.

[12] Sickinger C, Herrmann A. Structural Stitching as a Method to design HighPerformance Composites in Future Hermann von Helmholtz Group of German Research Centres. 2001.

[13] Shah Darshil U, Schubel Peter J, Clifford Mike J. Can flax replace E-glass in structural composites? A small wind turbine blade case study. Compos Part
Eng 2013;52:172-81.

[14] Zarouchas DS, Makris AA, Sayer F, Van Hemelrijck D, Van Wingerde AM. Investigations on the mechanical behavior of a wind rotor blade subcomponent. Compos Part B - Eng 2012;43:647-54.

[15] Ganz Stephen. Finite element analysis of steel and composite gusset plates in a warren truss bridge using Abaqus. Eng Rep 2012.

[16] Dai Gaoming, Mishnaevsky Jr Leon. Carbon nanotube reinforced hybrid composites: computational modeling of environmental fatigue and usability for wind blades. Compos Part B- Eng 2015;78:349-60.

[17] Zou GP, Shahin K, Taheri F. An analytical solution for the analysis of symmetric composite adhesively bonded joints. Compos Struct 2004;65:499-510.

[18] Herman SA. Analysis of transport and installation costs. Offshore Wind Farms 2002. Vol. ECN-I-;02-002.

[19] Ikeda, T. 1992. Fiber-reinforced composite cable. US Patent 5,130,193.

[20] Chou Jui-Sheng, Chiu Chien-Kuo, Huang I-Kui, Chi Kai-Ning. Failure analysis of wind turbine blade under critical wind loads. Eng Fail Anal 2013;27:99-118.

[21] Cox Kevin, Echtermeyerb Andreas. Structural design and analysis of a 10MW wind turbine blade. Energy Procedia 2012;24.

[22] Cox Kevin, Echtermeyer Andreas. Geometric scaling effects of bend-twist coupling in rotor blades. Energy Procedia 2013;35:2-11.

[23] Hayat Khazar, Ha Sung Kyu. Load mitigation of wind turbine blade by aeroelastic tailoring via unbalanced laminates composites. Compos Struct 2015;128:122-33.

[24] Subrahmanian KP, Dubouloz Fabrice. Adhesives for bonding wind turbine blades. Reinf Plast 2009;53:26-9.

[25] Tong L, Jain LK. Analysis of adhesive bonded composite lap joints with transverse stitching. Appl Compos Mater 1995;2.

[26] Leone Frank A, Girolamo Jr Donato, Davila Carlos G. Progressive damage analysis of bonded composite joints. Tech Report 2012

[27] Lobitz Don W, Veers Paul S. Aeroelastic behavior of twist-coupled hawt blades. In: ASME wind energy symposium AIAA-98-0029; 1998.

[28] Kim MS, Park CY, S. M.. Failure analysis of adhesively bonded joints consisting of bi-layer composites. In: 18th International conference on composite materials; Jun. 2011.

[29] Shokrieh Mahmood M, Rafiee Roham. Simulation of fatigue failure in a full composite wind turbine blade. Compos Struct 2006;74:332-42.

[30] Bechly ME, Clausent PD. Structural design of a composite wind turbine blade using finite element analysis. Comput Struct 1997;63:39-616.

[31] Muthirakkal s, Narasimha murthy hnr, Krishna m.-Rai ks, Karippal jj. Hygrothermic behaviour of carbon/vinylester, glass/vinylester, carbon/epoxy and glass/epoxy composites. Iran Polym J 2010;19. 2(116).

[32] of defense, Department. In: Composite materials handbook, Volume 2 of 5; 1999.

[33] Patten Sam. Targeting composite wing performance optimising the composite lay-up design. Altair Eng 2009. 16-1.

[34] Veers Paul S, Ashwill Thomas D, Sutherland Herbert J, Laird Daniel L, John F, Mandell, et al. Trends in the design, manufacture and evaluation of wind turbine blades. Wind energy 2003;6:245-59.

[35] Stickler PB, Ramulu M, Johnson PS. Experimental and numerical analysis of transverse stitched T-joints in bending. Compos Struct 2000;50.

[36] Joven R, Das R, Ahmed A, Roozbehjavan P, Minaie B. In: Thermal properties of carbon fiber-epoxy composites with different fabric weaves Conference paper; 2012

[37] Sawyer James Wayne. Effect of stitching on the strength of bonded composite single lap joints. AIAA J 1985;24.

[38] S.Smeltzer. Stanley. 2006. Analytical and Numerical Results for an Adhesively Bonded Joint Subjected to Pure Bending. 47th Aiaa/Asme/Asce/Ahs/Asc Structures, Structural Dynamics, and Materials Conference.

[39] Taghavi Shahriar Ghavidel. Moisture effects on high performance polymer composites. 2000.

[40] Ushijima, K. 2010. Cable made of high strength fiber composite material. US Patent 7,650,742.

[41] Hua Yi, Kasavajhala Ananth Ram Mahanth, Gu Linxia. Elasticplastic analysis and strength evaluation of adhesive joints in wind turbine blades. Compos Part B - Eng 2013;44:650-6.

[42] Li Zhimin, Li Chun, Gao Wei, Wu Yulong. Effect of layup design on properties of wind turbine blade. Front Eng Mech Res 2013;2. 